\title{
Effect of Plastic Pre-straining on Residual Stress and Composition Profiles in Low- Temperature Surface-Hardened Austenitic Stainless Steel
}

Bottoli, Federico; Christiansen, Thomas Lundin; Winther, Grethe; Somers, Marcel A. J.

Published in:

Metallurgical and Materials Transactions A: Physical Metallurgy and Materials Science

Link to article, DOI:

$10.1007 / \mathrm{s} 11661-016-3586-4$

Publication date:

2016

Document Version

Peer reviewed version

Link back to DTU Orbit

Citation (APA):

Bottoli, F., Christiansen, T. L., Winther, G., \& Somers, M. A. J. (2016). Effect of Plastic Pre-straining on Residual Stress and Composition Profiles in Low-Temperature Surface-Hardened Austenitic Stainless Steel. Metallurgical and Materials Transactions A: Physical Metallurgy and Materials Science, 47(8), 4001-4011. https://doi.org/10.1007/s11661-016-3586-4

\section{General rights}

Copyright and moral rights for the publications made accessible in the public portal are retained by the authors and/or other copyright owners and it is a condition of accessing publications that users recognise and abide by the legal requirements associated with these rights.

- Users may download and print one copy of any publication from the public portal for the purpose of private study or research.

- You may not further distribute the material or use it for any profit-making activity or commercial gain

- You may freely distribute the URL identifying the publication in the public portal 


\title{
Effect of plastic pre-straining on residual stress and composition profiles in low-temperature surface hardened austenitic stainless steel
}

\author{
Federico Bottoli, Thomas L. Christiansen, Grethe Winther, Marcel A.J. Somers \\ Technical University of Denmark, Department of Mechanical Engineering, \\ Produktionstorvet b.425, 2800 Kgs. Lyngby, Denmark \\ E-mail: febot@mek.dtu.dk, tch@mek.dtu.dk, grwi@mek.dtu.dk, somers@mek.dtu.dk
}

Phone: +4545252250

Corresponding author: Marcel A.J. Somers, somers@mek.dtu.dk

Phone: +4545252250

Fax: +4545936213

\section{Keywords}

Low-temperature surface hardening, x-ray diffraction, residual stresses, expanded austenite, nitriding, carburizing, nitrocarburizing 


\section{Abstract}

The present work deals with the evaluation of the residual-stress profiles in expanded-austenite by applying grazing incidence X-ray diffraction (GI-XRD) combined with successive sub-layer removal. Annealed and deformed $\left(\varepsilon_{\mathrm{eq}}=0.5\right)$ samples of stable stainless steel EN 1.4369 were nitrided or nitrocarburized. The residual stress profiles resulting from the thermochemical low-temperature surface treatment were measured. The results indicate high residual compressive stresses of several GPa's in the nitrided region, while lower compressive stresses are produced in the carburized case. Plastic deformation in the steel prior to thermochemical treatment has a hardly measurable influence on the nitrogen-rich zone, while it has a measurable effect on the stresses and depth of the carbon-rich zone.

\section{Introduction}

Surface engineering techniques are widely used to modify material surface properties. Through thermal, mechanical and chemical surface treatments, it is possible to tailor the resistance against wear, corrosion and fatigue, and thus enhance the component performance [1]. Most surface engineering techniques are associated with the introduction of residual stress-depth profiles, which can have a detrimental or a favourable effect on the performance of materials and components under certain conditions [2].

Among surface engineering techniques, a growing interest is observed in low-temperature gaseous processes of stainless steels, because, compared to existing treatments, these techniques allow a significant improvement of wear and fatigue resistance, without impairing (but rather improving) the material's corrosion performance [3-5].

The significant improvement of the material surface properties after low-temperature nitriding (LTN), nitrocarburizing (LTNC) or carburizing (LTC) is due to the dissolution of a colossal amount of nitrogen and/or carbon in the stainless steel matrix, forming a supersaturated solid solution known as expanded austenite $[6,7]$. The interstitial concentration profile of the dissolved nitrogen and carbon atoms has been reported to lead to the development of enormous compressive residual stresses in the near surface region parallel to the material's surface, from 2-3 GPa after carburising up to $8 \mathrm{GPa}$ after nitriding [8-10].

The composition-induced stresses are usually evaluated by angle dispersive diffraction methods using the radiation produced by conventional X-ray tubes. Quantitative assessment of residual stresses in expanded 
austenite is challenging as the several properties influencing the lattice spacing measured in an X-ray diffraction experiment can change considerably within the depth range probed in an experiment [2]. (Steep) gradients in the local lattice spacing, as a consequence of gradients in composition, stress and stacking fault density can have a significant effect on the result obtained in residual stress determination [2,9-11]. Furthermore, elastic constants [9] and thermal expansion coefficients [12] (and magnetic properties [13]) depend strongly on the interstitial content dissolved in expanded austenite. Extensive research has been carried out with both destructive and non-destructive XRD methods to evaluate the magnitude of the compressive stresses and to take into account the influence of the various parameters $[8-11,14,15]$

The conventional " $\sin ^{2} \psi$ " method, using symmetric Bragg-Brentano geometry, leads to a significant variation of the information depth of the X-rays with tilt angle. This variation leads to the generation of ghost or fictitious stresses that have to be taken into account and corrected for in the data evaluation procedure [11]. Alternatively, the influence of ghost stresses can be reduced by a proper choice of the measurement geometry (not Bragg-Brentano). Recently it was shown for fixed grazing-incidence angles, that the probed depth range is shallow and the resulting information depth can be assumed constant $[9,16]$.

In industrial practice, the presence of residual plastic deformation in the near surface region prior to surface treatment is the rule rather than the exception and may have a strong influence on the low-temperature thermochemical processes [17-19]. In the present study the influence of such residual plastic deformation in the steel on residual-stresses developing in expanded austenite upon nitriding and nitrocarburizing is investigated.

\subsection{X-ray diffraction stress analysis}

X-ray measurements allow the determination of the stress state in a crystalline phase by measuring the variation of the interplanar spacing in directions along different diffraction vectors with respect to the sample's geometry. X-ray stress evaluation is based on the determination of lattice strains assuming isotropic elasticity theory.

In polycrystalline materials, only the crystallites with their lattice plane normal parallel to the diffraction vector contribute to the diffracted intensity [20]. The contribution of a certain depth under the surface to the diffracted intensity depends on the absorption of incident and diffracted intensity and the path as adjusted by the diffraction geometry [2]. The crystallites closer to the surface have a stronger contribution while the ones 
deeper in the material will contribute less to the line profile [2]. Therefore, the lattice spacing determined is the diffracted intensity-weighted d-spacing value, which can be simplified to:

$$
d=\frac{\int_{0}^{\infty} d(z) \exp \left(-\frac{z}{\tau}\right) d z}{\int_{0}^{\infty} \exp \left(-\frac{z}{\tau}\right) d z}
$$

where $\mathrm{z}$ is depth and $\tau$ is the information depth, which actually is identical to the diffracted intensity-weighted depth. The relationship between the lattice strain in a crystallite with orientation $h k l$ and the stress is expressed by:

$$
\begin{aligned}
& \varepsilon_{\varphi \psi}=\frac{\left(d_{\varphi \psi}^{h k l}-d_{0}^{h k l}\right)}{d_{0}^{h k l}}= \\
& 1 / 2 S_{2}(h k l)\left[\sigma_{11} \cos ^{2} \varphi \sin ^{2} \psi+\sigma_{22} \sin ^{2} \varphi \sin ^{2} \psi+\sigma_{33} \cos ^{2} \psi\right]+1 / 2 S_{2}(h k l)\left[\sigma_{12} \sin 2 \varphi \sin ^{2} \psi+\right. \\
& \left.\sigma_{13} \cos \varphi \sin 2 \psi+\sigma_{23} \sin \varphi \sin 2 \psi\right]+S_{1}(h k l)\left[\sigma_{11}+\sigma_{22}+\sigma_{33}\right]
\end{aligned}
$$

where $d_{\varphi \psi}^{h k l}$ is the lattice spacing for the $h k l$ planes in a direction defined by the rotation angle $\varphi$ and the tilt angle $\psi$ with respect to the frame of reference formed by the principal stresses, $d_{0}^{h k l}$ is the strain-free lattice spacing, and $1 / 2 S_{2}(h k l)$ and $S_{1}(h k l)$ are the X-ray elastic constants (XECs) for the $h k l$ under consideration.

The stress state resulting from a thermochemical treatment can usually be assumed biaxial. Hence, $\sigma_{11}=\sigma_{22}=\sigma_{\|}$and $\sigma_{33}=0$ and Equation 2 can be rewritten as follows:

$$
\varepsilon_{\varphi \psi}^{h k l}=\frac{\left(d_{\varphi \psi}^{h k l}-d_{0}^{h k l}\right)}{d_{0}^{h k l}}=1 / 2 S_{2}^{h k l} \sigma_{\|} \sin ^{2} \psi+2 S_{1}^{h k l} \sigma_{\|}
$$

Equating Equation 3 to zero and rearranging the terms, allows finding the strain free spacing $d_{0}^{h k l}$ probed for the strain free direction $\psi_{\varepsilon=0}$ :

$$
\sin ^{2} \psi_{\varepsilon=0}=\frac{-2 S_{1}^{h k l}}{1 / 2 S_{2}^{h k l}}
$$

Equation 4

The conventional " $\sin ^{2} \psi$ " method, using symmetric Bragg-Brentano geometry, is characterized by a significant variation of the information depth with the tilt angle, such that the depth range analysed is reduced with increasing tilt angle. Consequently, if a lattice spacing-depth profile occurs as a consequence of a 
composition and/or a stress profile, the conventional " $\sin ^{2} \psi$ " method combines experimental lattice spacings obtained for different information depths in one determination of the stress, thereby introducing artefacts leading to fictitious stress values, so-called ghost stresses, in addition to the actual stress value.

Conversely, asymmetric geometry (grazing incidence mode) allows a small fixed (or tilt dependent) incidence angle, limiting the probed depth range to a shallow region in the proximity of the surface. By the application of a fixed grazing incidence, the information depth varies to a limited extent, while by tailored variation of the incidence angle with the tilt angle a constant information depth can be achieved [21,22].

On applying grazing incidence mode, it has to be taken into account that the lattice spacing is probed in a direction that is tilted with respect to the surface normal, even for no actual rotation. The effective tilt angle $\psi$ is given by:

$$
\cos \psi=\cos \chi \cos (\theta-\alpha)
$$

Equation 5

where $\chi$ is the tilt angle in the laboratory frame of reference. Hence, asymmetric geometry set-up does not require correction procedures, which would have been the case for measurement in symmetric geometry mode, where gradients may strongly affect the obtained lattice spacings.

\subsection{X-Ray elastic constants}

For any practical applications, the knowledge of the X-ray elastic constant is a necessary prerequisite for the determination of the stress-state of the material. The diffraction elastic constant can be obtained from singlecrystal elastic constants through the use of grain interaction models (GIM). Several grain interaction models have been proposed in literature [21]. The Voigt [23] and Reuss [24] grain interaction models are considered the two extreme models. The Voigt GIM assumes that the strain distribution is homogenous in the specimen, while the Reuss GIM assumes that the stress tensor is equal for all crystallites. The two extreme cases of GIM in polycrystals were proven by Hill to set the upper and lower bounds for the mechanical elastic constants. The Neerfeld-Hill model $[25,26]$ suggests that the arithmetic average of the Voigt and Reuss models is in better agreement with experimental data. The Vook-Witt and the inverse VookWitt models [27] include extreme grain interaction assumptions along the two considered principal directions. For special conditions at the free surface the Vook-Witt model assumes equal strains in the surface plane and zero stress perpendicular to the surface; the inverse Vook-Witt model assumes equal strain perpendicular to the surface and equal stresses in the surface plane. Eventually, in the Eshelby-Kröner 
model [28,29] the crystallites surrounding an individual crystallite are conceived as an elastically homogenous matrix with averaged elastic properties of the entire polycrystal. The determination of the single-crystal elastic constant is therefore an essential prerequisite for the calculation of X-ray elastic constants for polycrystals, irrespective of the GIM adopted.

So far, single crystal elastic constants have not been determined for expanded austenite; therefore, the elastic constants reported for stainless steel $\mathrm{Fe}-12 \% \mathrm{Cr}-12 \% \mathrm{Ni}$ are often used $[9,10,15]$. However it has been shown that the presence and the amount of interstitial atoms in solid solution has an enormous influence on the X-ray elastic constant, and in particular that the ratio $E_{200} / E_{111}$ grows substantially with the growing content of dissolved atoms [9]. Furthermore, recent work on the magnetic properties of nitrogen stabilized expanded austenite [13], shows that depending on the nitrogen content and the temperature, expanded austenite is paramagnetic or ferromagnetic and has a Curie temperature in-between the nitriding temperature and room temperature. As magnetic and elastic properties are coupled it is anticipated that also the elastic properties of nitrogen stabilized expanded austenite are different at nitriding and room temperature.

In the present work, the X-ray elastic constants of paramagnetic $\mathrm{Fe}-12 \% \mathrm{Cr}-12 \% \mathrm{Ni}$ and ferromagnetic $\gamma^{\prime}-\mathrm{Fe}_{4} \mathrm{~N}$ (Table 1) were calculated, using the Reuss GIM. These values were used for the evaluation of residual stresses in expanded austenite which are expected to be representative for a low (paramagnetic) and intermediate to high (ferromagnetic) interstitial content. Changing the crystal structure from $\gamma-\mathrm{Fe}$ to $\gamma^{\prime}-\mathrm{Fe}_{4} \mathrm{~N}$ a reversal of the elastic anisotropy occurs [23]; a similar reversal was observed for expanded austenite with low and high interstitial content [9,30]. The motivation for adopting the Reuss GIM was the good correspondence of the obtained stress profiles for the 111 and 200 family planes in previous work [9].

\section{Experimental}

\subsection{Materials preparation}

The stainless steel EN 1.4369 with chemical composition Fe-0.09C-0.23N-0.74Si-0.18Mo-5.92Mn-18.58Cr$7.11 \mathrm{NI}(w t \%)$ was investigated in this experimental activity. The supplier provided the material in annealed condition as $0.7 \mathrm{~mm}$ thick plate. Tensile test specimens were cut out from the plate material in accordance to 
the ASTM standard E 8M-0419. The tensile loading direction was chosen parallel to the rolling direction of the plate. Tensile straining was applied at a strain rate of $6.67 \times 10^{-3} \mathrm{~s}^{-1}$ to an equivalent strain of $\varepsilon_{\mathrm{eq}}=0.5$. The texture of the material was measured by EBSD, revealing a weak fcc rolling texture typical for low-stackingfault materials in the undeformed state. The frequency of $\langle 100\rangle$ and $\langle 110\rangle$ poles along the normal direction of the rolled sheet was less than 1.4 times random. The deformation induced a typical strong tensile texture with accumulation of $<111>$ and $<100>$ poles along the tensile axis, thereby increasing the frequency of $<110>$ poles along the sheet normal. This is in agreement with the observed increasing intensity of the 220 peak as compared to 111 and 200 in the X-ray diffraction after deformation [17].

Specimens with dimensions $15 \times 12.5 \times 0.7 \mathrm{~mm}^{3}$ were obtained from the annealed and deformed material. The flat surface of the specimens was ground and polished to a final step of $3 \mu \mathrm{m}$ diamond paste and afterwards electro-polished in order to remove the plastic deformation zone introduced by grinding. The electropolishing was carried out for 20 s in a "Struers Electrolyte A2" solution with an applied potential and current density of $30 \mathrm{~V}$ and $2 \mathrm{~A} / \mathrm{cm}^{2}$, respectively.

\subsection{Low-temperature thermochemical processes}

Samples in annealed and deformed state were subjected to two different treatments: nitriding (LTN) and nitrocarburizing (LTNC). The low-temperature nitriding and nitrocarburizing processes were performed in a LAC annealing furnace model PKRC 55/09 retrofitted for gaseous nitriding/nitrocarburizing. The samples were suspended on a type $\mathrm{K}$ (chromel/alumel) thermocouple to monitor the temperature during the entire nitriding cycle, including heating and cooling. To enable low-temperature surface hardening, the sample surface was activated in-situ by a proprietary procedure. The nitriding process was carried out in a pure ammonia atmosphere at $703 \mathrm{~K}\left(430^{\circ} \mathrm{C}\right)$ for $20 \mathrm{~h}$ while the nitrocarburizing was carried out in an ammonia/propane gas mixture at $693 \mathrm{~K}\left(420^{\circ} \mathrm{C}\right)$ for $20 \mathrm{~h}$. Attempts to carburize EN 1.4369 did not succeed for the annealed condition of the steel, despite various procedures of surface activation. It is anticipated that the presence of nitrogen in the as-received condition of this alloy is responsible for this inability to dissolve carbon. For this reason carburized samples are not included in this investigation.

\subsection{Microstructural characterization}


The microstructures of all samples before and after low-temperature thermochemical processes were investigated in cross section with reflected-light microscopy. The samples were ground, polished and etched with Kalling's reagent no.1 for 5-8 s. Micro-hardness indentation measurements to obtain the hardness profile over the "case" were performed on a Future-Tech FM700 instrument using a load of $0.05 \mathrm{~N}$.

Glow discharge optical emission spectroscopy (GD-OES) was applied for the determination of the surface composition profiles after the low-temperature thermochemical treatments. Controlled sputtering of the surface during GD-OES was performed with a plasma at 1000Pa and 40W using a Horiba Jobin Yvon GD profiler 2. Quantitative concentration profiles of substitutionally and interstitially dissolved components were obtained using a selection of stainless steel reference materials and $\gamma^{\prime}-\mathrm{Fe}_{4} \mathrm{~N}$ on pure iron as a nitrogen reference.

\subsection{X-ray diffraction stress depth profiling}

X-ray diffraction analysis was performed with a Bruker AXS D8 diffractometer equipped with Cr-tube source with a characteristic wavelength of $2.2897 \AA$. A voltage of $40 \mathrm{kV}$ and a current of $40 \mathrm{~mA}$ were used for the measurements. The lattice spacing profiling for residual stress analysis over the thickness of the hardened surface was determined in grazing incidence geometry using point focus configuration and a vanadium window to remove $\mathrm{Cr} \mathrm{K}_{\beta}$. Although it is considered good practice to use high $2 \theta$ angles for the evaluation of residual stresses the 220 and 311 reflections were too weak and broad to guarantee an accurate evaluation of the stress profiles. The possible instrumental influence of applying reflections in the low $2 \theta$ range was determined: stress-free stainless steel powder was measured resulting in "stress-values" less than 100MPa. This contribution is negligible as compared to the stress values to be determined in the present case. The measurements were performed in a range $55^{\circ}-85^{\circ} 2 \theta$. This range was selected to include the 111 and 200 reflections of austenite and expanded austenite. The step size was $0.05^{\circ} 2 \theta$ and the counting time was $6 \mathrm{~s}$ per $2 \theta$ step. The grazing incidence angle was kept fixed at $\alpha=2^{\circ}$ for all the tilting angles $\chi$. Line profiles were obtained for 5 values of $\chi$ angle $\left(0^{\circ}, 25^{\circ}, 38^{\circ}, 49^{\circ}, 60^{\circ}\right)$. Keeping a small fixed grazing incidence angle can limit the probed volume to a shallow surface region. However, even for fixed grazing incidence angles, the information depth changes with $\psi$ angle. This small variation in the penetration depth, which is from 0.18 to $0.35 \mu \mathrm{m}$ in the investigated $2 \theta$ range, is responsible for the generation of substantial ghost stresses especially in the near surface region area, where a very steep gradient in the lattice parameter is present 
because of the steep nitrogen concentration profile. After each measurement, a thin sublayer of approximately $1.5 \mu \mathrm{m}$ of expanded austenite was removed by gentle polishing with $3 \mu \mathrm{m}$ diamond paste. The sublayer removal procedure was performed on each of the analysed samples until the material substrate was reached (no $2 \theta$ shift of the substrate reflection was recorded). During polishing the sample was constantly rotated in order to secure uniform removal of material over the selected surface. The weight loss was measured several times for each polishing step with a high precision balance. This allowed an accurate control of the sub layer removal for each polishing step. The accuracy of the removed sublayer thickness is estimated to be within $0.1 \mu \mathrm{m}$.

The 111 and 200 X-ray line profiles of each sample as collected at the different depths were fitted to determine the centroid position of the Bragg peak. From the centroid position it was possible to calculate the as-measured lattice spacing values $\left\langle d_{\varphi \psi}^{h k l}\right\rangle$ for the 111 and 200 reflections. In the transition regions from $\gamma_{N}$ to $\gamma_{C}, \gamma_{N}$ to $\gamma$ and from $\gamma_{C}$ to the $\gamma$ core, the centroid peak position contained contributions from $\gamma_{N}$ and $\gamma_{C}, \gamma_{N}$ and $\gamma$ and from $\gamma_{c}$ and $\gamma$, respectively. Away from these transition regions the centroid position can be exclusively attributed to $\gamma_{\mathrm{N}}, \gamma_{C}$ or $\gamma$. The $\sin ^{2} \psi$ plots for the 111 and 200 reflections were constructed by fitting straight lines through the as-determined lattice spacing, $\left\langle d_{\varphi \psi}^{h k l}\right\rangle$ vs. the corresponding $\sin ^{2} \psi$ value, yielding the slope, $\Delta\left\langle d_{\psi}^{h k l}\right\rangle / \Delta \sin ^{2} \psi$, and intercept, $\left\langle d_{\psi=0}^{h k l}\right\rangle$.

\section{$3 \quad$ Results}

\subsection{Low-temperature nitriding}

EN 1.4369 in annealed and deformed condition was subjected to low-temperature gas nitriding at $703 \mathrm{~K}$ $\left(430^{\circ}\right)$ for $20 \mathrm{~h}$ in pure ammonia. Reflected light microscopy (Fig.1) reveals the morphology of the case produced during the process. In both conditions a uniform layer of expanded austenite with a thickness of $10( \pm 1) \mu \mathrm{m}$ is found in the outermost surface. XRD phase analysis in Bragg-Brentano geometry confirms the formation of expanded austenite during the low-temperature gaseous process (Fig. 2). In the $2 \theta$ range investigated it is possible to identify the expanded austenite and the austenite peaks. The peaks of the expanded austenite are shifted to lower $2 \theta$ compared to the parent austenite phase, because of the lattice expansion provoked by the nitrogen dissolution. As observed in the micrographs, no significant difference in 
the degree of expansion of austenite can be observed in the X-ray diffractograms of the annealed and deformed sample, consistent with previous work, which indicated that EN 1.4369 consists of stable austenite [17].

The GD-OES profiles in Fig. 3 confirm the presence of a nitrogen-rich zone in proximity of the surface. The atomic concentration of nitrogen at the surface is close to about $40 \%$ and decreases steeply approaching the composition of the parent austenite at about $11 \mu \mathrm{m}$. The carbon peaks ahead of the nitrogen concentration profiles are attributed to the accumulation of carbon originally present, indicating that nitrogen strongly enhances the activity of carbon. This phenomenon is generally observed on nitriding of carbon-containing steels (cf. discussion in [19]). A trend is observed that the nitrogen depth profile reaches deeper for the strained condition than for the annealed condition (Fig. 3).

For the evaluation of the residual stresses in the materials, the lattice spacing values $\left\langle d_{\varphi \psi}^{h k l}\right\rangle$ were measured for the 111 and 200 reflections and from these the $\sin ^{2} \psi$ plots were calculated. In Fig. 4a the slopes for the 111 and 200 peaks for both the annealed and strained conditions are given. The values of the slopes are more negative at the surface, indicating high compressive stresses in these regions, and they increase smoothly to less negative values (lower compressive stresses) on approaching the parent austenite. Eventually they stabilize to slightly negative values after $10 \mu \mathrm{m}$. It is noted that more negative values of the slopes are found for the 200 reflection than for the 111 reflection, suggesting strong elastic anisotropy such that 200 is more sensitive for applied stress than 111 , i.e. $1 / 2 S_{2}^{200}>1 / 2 S_{2}^{111}$.

The calculated intercept values (Fig. 4b) decrease smoothly throughout the layer thickness and reach a plateau for depths after $10 \mu \mathrm{m}$. These observations are in agreement with the micrographs in Fig. 1 and the composition profiles in Fig.3. Evidently, within experimental accuracy no difference can be discerned between the annealed and deformed cases. Apparently, the presence of plastic deformation prior to lowtemperature nitriding does not have a measurable influence on the compressive stresses induced by gaseous nitriding. Furthermore, the slightly deeper nitriding front as suggested by the GD-OES profiles in Fig. 3 were not confirmed by the stress measurements, most likely as a consequence of the experimental accuracy (see error bars in Figs. 4).

\subsection{Low-temperature nitrocarburizing}


EN 1.4369 in annealed and deformed condition was subjected to low-temperature gas nitriding at $693 \mathrm{~K}$ $\left(420^{\circ}\right)$ for $20 \mathrm{~h}$ in a controlled ammonia/propene atmosphere. For both samples the nitrogen expanded austenite is lying closest to the surface, while the carbon expanded region is located underneath. Even for low-temperature nitrocarburizing no significant difference can be discerned between the annealed and deformed sample in the reflected light microscopy analysis (Fig. 5). X-ray diffraction analysis (Fig. 6) confirms the formation of separate zones with nitrogen and carbon expanded austenite in both samples. In this case, reflections from the substrate are no longer visible due to a thicker case and the limited depth probed by the applied X-radiation.

The GD-OES and hardness profiles for the annealed and deformed state are given in Figs. 7-8. The GDOES measurement confirms the transition from a separate nitrogen-rich to a separate carbon-rich zone (Fig. 7). As for the nitrided samples a trend is observed that the nitrogen stabilized expanded austenite reaches slightly deeper for the strained sample than for the annealed sample. This trend is more pronounced for the carbon stabilized expanded zone. For the strained sample the carburized part reaches more than $3 \mu \mathrm{m}$ deeper than for the annealed sample. Analogous to LTN, carbon is accumulated ahead of the nitrogen front, albeit to significantly higher contents than with LTN (cf. Fig. 3), because in addition to carbon superseded to larger depth, now also carbon is added from the nitrocarburizing gas. The total interstitial content as determined by GD-OES is compared to the hardness profiles over the case in Fig. 8. Clearly, the hardness scales with the total interstitial content until a level of $1200 \mathrm{HV}$ is reached. This is particularly clear for the strained sample where the discontinuous decrease in interstitial content on entering the carbon-rich zone is associated by a discontinuous decrease in micro-hardness. For both annealed and strained conditions, the hardness in the nitrogen-rich region is significantly higher than in the carbon-rich region. The hardness profiles show that the carbon-stabilized expanded phase bridges the hardness difference between the nitrogen expanded part of the case to the core and therefore a smooth decrease in hardness to the bulk hardness value is obtained over several microns. This differs considerably from what is obtained during LTN, where the case-to-core transition occurs within few microns and a sharp hardness transition is measured [5]. From the $\sin ^{2} \psi$ plots the slopes and intercepts were obtained (see Fig. 9a and 9b, respectively). For both conditions (annealed and deformed samples), more negative values of the slope are found in the nitrided region; subsequently the slopes increase rapidly deeper in the case, indicating a considerable reduction of the compressive stresses. Eventually, in carbon stabilized expanded austenite at depths of more than about 
$8 \mu \mathrm{m}$, the slopes increase slightly but steadily until levelling off at a slightly negative value in proximity of the bulk. The trends of the slopes of the 111 and 200 reflections in the nitrogen expanded region of the annealed and deformed sample are similar (Fig. 9a), but a consistent difference can be observed in the carbon-rich expanded austenite zone. In this region the values of the slopes are always more negative for the strained than for the annealed condition, indicating that larger compressive stresses are present in pre-strained carbon expanded austenite. The intercepts of the $\sin ^{2} \psi$ plots decrease continuously with increasing depth (Fig. 9b). Clearly a steeper decrease in intercept is found in the nitrogen-rich than the carbon-rich region, consistent with the change in total interstitial content and hardness in Fig. 8.

\section{Discussion}

\subsection{Stress profiles and stress-free lattice parameters}

The Reuss GIM was applied for the evaluation of the strain-free lattice parameters and the stress profiles for the annealed and strained materials after the surface engineering processes (LTN, LTNC). The X-ray elastic constants of austenite and $\gamma^{\prime}-\mathrm{Fe}_{4} \mathrm{~N}$ were used for the calculation (cf. section 1.2). The measured lattice spacings were used for the evaluation of the strain-free lattice parameters using the relations $\left\langle a^{111}\right\rangle=$

$\left\langle d_{\psi=0}^{111}\right\rangle \cdot \sqrt{3}$ and $\left\langle a^{200}\right\rangle=\left\langle d_{\psi=0}^{200}\right\rangle \cdot 2$. The strain-free direction is determined by the ratio of the $\mathrm{X}$-ray elastic constants (Eq. 4). In Fig. 10 the strain-free lattice parameters derived from 111 and 200 reflections are given for the investigated samples, using the XECs for austenite (Fig. 10a) and $\mathrm{Fe}_{4} \mathrm{~N}$ (Fig. 10b). As seen in the figures, the two sets of XECs give almost the same results. The difference between the strain-free lattice parameters obtained from 111 and 200 is less than $1 \%$ of the average in all cases. Evidently, the strain-free lattice parameter profiles obtained for the 111 and 200 reflections are in good agreement with each other, irrespective of the chosen X-ray elastic constants, despite variation in strain-free direction (cf. XECs in Table 1). This relative insensitivity for the XEC ratio indicates that the change in lattice spacing is governed by the change in composition rather than the lattice strain. As follows from Fig.10, the dependence of the strainfree lattice parameter on depth in the nitrogen-rich part is analogous for nitrided and nitrocarburized samples, while a marked difference is obtained in the carbon-rich part, i.e at depths larger than about $8 \mu m$. 
Here the strain-free lattice parameter does not decrease as steeply as in the nitrogen-rich part and a deeper case is obtained, consistent with the GD-OES profiles in Figs. 3 and 7 and the micrographs in Figs. 1 and 5. The slopes obtained from the $\sin ^{2} \psi$ plots were used for the calculation of the stress profiles for the various process conditions (Fig. 11). Not surprisingly, a significant influence is observed of the X-ray elastic constants on the measured stress profiles over the depth. As was already concluded in section 3.1, agreement between the stresses evaluated from 111 and 200 could only be expected for $1 / 2 S_{2}^{200}>1 / 2 S_{2}^{111}$, as for the XECs of austenite (Table 1), while $1 / 2 S_{2}^{200}<1 / 2 S_{2}^{111}$, as for the XECs of $\gamma^{\prime}-\mathrm{Fe}_{4} \mathrm{~N}$, can only lead to a divergence of the stress values derived from 111 and 200. The profiles measured using the Reuss GIM and the XECs for stainless steel show a fair correspondence for the 111 and 200 reflections (Fig. 11a). High compressive residual stresses result in the nitrogen-rich region of the case as the result of a high amount of nitrogen content. In the carbon-rich regions lower compressive stresses are obtained, consistent with a lower amount of dissolved interstitials. The decline of compressive stress with the increasing depth is steep in the nitrogen-expanded region, while for the carbon-expanded region a more gradual decrease is observed along the case. These observations reflect what has been observed in the GDOES and hardness profiles (cf. Fig. 3, 7 and 8). The data in Fig. 11a (and b) were not corrected for the stress redistribution caused by successive removal of thin highly compressive stress layers by polishing. This stress redistribution leads to an additional compressive component in the measured lattice strain. Application of the correction method proposed by Moore and Evans [30] showed that this omission will change the stress values at the largest depths probed in Fig.11a by up to $180 \mathrm{MPa}$ (additional compression), which is about the size of the markers in Fig. 11a and is commensurate with the error involved in the stress determination in the present system. For this reason uncorrected data are presented.

Close to the case-core transition positive values of stress are obtained. Notwithstanding the fact that a positive stress has to be expected in the unaffected core to compensate for the large compressive stresses in the case, tensile stresses can equally well be conceived as merely an effect of the measurement and data evaluation procedures. In this region, the calculated values are significantly influenced by using the centroid position for the line profile evaluation, loss of linearity of the experimental $d_{\psi}-\sin ^{2} \psi$ dependence and, for the steep gradients, ghost stress effects. Therefore, it is not possible to conclude whether the obtained values are actual tensile stresses or just an artefact of the applied measurement and data evaluation procedures. 
Applying the XECs of $\gamma^{\prime}-\mathrm{Fe}_{4} \mathrm{~N}$, a major discrepancy between the stress values obtained from the probed reflections was found for the Reuss GIM (Fig. 11b). Obviously, the stress values calculated for the 200 reflection are unrealistically high; values of compressive stress up to $15.5 \mathrm{GPa}$ in the case formed upon lowtemperature surface treatment cannot be subtended by this material. This major discrepancy suggests that the X-ray elastic constants for iron-nitride, in combination with the Reuss GIM, are not suitable for the evaluation of the residual stresses in expanded austenite, despite the similarity in the crystal structures, interstitial nitrogen contents and magnetic properties of $\gamma_{\mathrm{N}}$ and $\gamma^{\prime}-\mathrm{Fe}_{4} \mathrm{~N}$. Apparently, the long-range ordering of nitrogen in $\gamma^{\prime}-\mathrm{Fe}_{4} \mathrm{~N}$ as opposed to short range ordering of nitrogen in austenite, has a strong influence of the elastic anisotropy. A slightly better correspondence between 111 and 200 with elastic constants as for $\gamma^{\prime}-$ $\mathrm{Fe}_{4} \mathrm{~N}$ is anticipated for the Voigt GIM. Then, the difference as observed in Fig. 4a will be reproduced, because the XECs for 111 and 200 are identical for the case of the Voigt GIM. It has been shown in previous research activities that the X-ray elastic constants for expanded austenite depend strongly on the nitrogen

content [9]. In particular the $1 / 2 S_{2}^{111} / 1 / 2 S_{2}^{200}$ ratio increases strongly with the nitrogen content. Consequently, despite a fair agreement of the stress profiles calculated with the $\gamma$-Fe XEC with the Reuss GIM, the present results can, at best, be used for a qualitative estimation of the stress distribution, but cannot be exploited for the calculation of the real profile distribution in expanded austenite.

\subsection{Influence of plastic deformation on stress in expanded austenite}

It is evident from the present results that, ahead of the nitriding front, within carbon expanded austenite residual stress changes gradually, and as such bridges the large difference in lattice parameter between nitrogen-stabilized and austenite. Qualitatively, the compressive residual stress level in carbon expanded austenite (Fig. 11) is higher in the strained sample than in the annealed sample. Apparently, for nitrogen expanded austenite no such difference in residual stress level between strain and annealed sample condition prior to nitriding/nitrocarburizing was observed. Different responses for nitrogen and carbon expanded austenite can be explained as follows.

On LTN, nitrogen dissolution results in the introduction of huge lattice strains corresponding to very large compressive stresses. Only part of the lattice expansion can be accommodated elastically. Along with an increase in interstitial content the (expanded) austenite is strengthened. Above a certain interstitial content 
the additional lattice strain corresponds to a residual stress increase that exceeds the additional yield strength. Such plastic deformation has been observed for nitriding in the form of a nitrogen dissolutioninduced lattice rotation, depending on the initial grain orientation $[31,33,34]$. The crystal rotation effect produced upon nitriding has many similarities [31] with the grain-orientation dependent lattice rotations of individual bulk grains measured in monotonic tensile tests in a number of materials [33-37]. These rotations are further traced to activation of specific grain orientation dependent slip-system combinations $[31,36,37]$. For carburizing such plastic accommodation has so far not been reported. Recent attempts to predict nitrogen profiles and stress profiles during nitriding incorporate crystal plasticity and strengthening, leading to realistic nitrogen-concentration profiles and stress-depth distributions [38].

In the materials tested in this experimental activity, the amounts of nitrogen dissolved during nitriding/nitrocarburizing are far beyond the level above which plastic deformation is introduced in expanded austenite and also larger than the amount estimated to correspond to an apparent plastic strain exceeding 0.2 [31]. This means that the additional deformation introduced during nitrogen expanded austenite formation can be significantly higher than the level of plastic deformation introduced during pre-straining. Assuming that the effect of plastic deformation prior to nitriding/nitrocarburizing on the GD-OES profiles in Fig. 3 and Fig. 7 is the result of faster interstitial (pipe) diffusion as a consequence of the high dislocation density, it can be understood that a possible effect of prior plastic deformation on the nitrogen-depth profile is obscured by the additional excessive plastic deformation introduced by the high nitrogen content itself. An effect of prestraining on the interstitial content and the associated residual stress can only be expected to be apparent for the region where lattice strains in the case are accommodated largely elastically and where no strong additional plastic deformation is induced by the dissolution of interstitials. For the LTN sample this region of (predominant) elastic accommodation of lattice strain is close to the case-core transition [41]. For the LTNC sample the lattice expansion in the carbon expanded austenite region is (largely) accommodated elastically. Consequently, the effect of pre-straining is most clearly observed at the case-core transition for the LTN sample and carbon expanded austenite region. Although not verified in the present work, it is anticipated that (plastic) pre-strain in austenite has a pronounced effect on the composition and stress profiles over the carbon-enriched region of a carburized sample. 


\section{Conclusion}

The evaluation of the residual stress from lattice strains was carried out using the Reuss grain interaction model (GIM), applying the X-ray elastic constants (XECs) for austenite and for $\gamma^{\prime}-\mathrm{Fe}_{4} \mathrm{~N}$, because the elastic constants for expanded austenite are not known. Despite strong similarities between the crystal structures of $\gamma^{\prime}-\mathrm{Fe}_{4} \mathrm{~N}$ and expanded austenite a major discrepancy was found between the residual stress values, resulting from lattice strains determined for 111 and 200 reflections. The XECs of $\gamma^{\prime}-\mathrm{Fe}_{4} \mathrm{~N}$ are incompatible with the experimentally determined anisotropy $1 / 2 S_{2}^{200}>1 / 2 S_{2}^{111}$. Application the XECs of austenite provides a fair correspondence between the residual stress profiles determined from lattice strains probed for 111 and 200 reflections.

Pre-strain in plastically deformed austenite has a negligible influence on the concentration and stress profiles developing in the nitrogen-enriched regions of the nitrided and nitrocarburized samples. In contrast, prestrain has a measurable effect on the stress and concentration profiles in the carbon-enriched region underneath the nitrogen-enriched region of the nitrocarburized sample. This difference is related to the additional plastic deformation induced as a consequence of the dissolution of colossal amounts of nitrogen, which dominates a possible effect of residual plastic deformation introduced prior to a low-temperature thermochemical process. Such additional plastic deformation is less dominant (or absent) for the carbon enriched region, wherefore an effect of pre-strain is observed there.

\section{Acknowledgements}

For the present research work, the authors would like to express their gratitude to the Research Fund for Coal and Steel for the financial support to the PressPerfect project. Furthermore the authors would like to thank Sandvik Materials Technology for providing the EN 1.4369 alloy used in the investigation.

\section{References}

[1] J.S. Burnell and P.K. Datta: Surface Engineering Casebook, $1^{\text {st }}$ ed., Woodhead Publishing Ltd, Cambridge, 1996. 
[2] V. Hauk: Structural and Residual Stress Analysis by Nondestructive Methods, Elsevier, 1997.

[3] T. Bell: Key Eng. Mater., 2008, vol. 373-374, pp. 289-95.

[4] H. Dong: Int. Mater. Rev., 2010, vol. 55, pp. 65-98.

[5] T.L. Christiansen and M.A.J. Somers: Int. J. Mater. Res. Former. Zeitschrift Fuer Met., 2009, vol. 100, pp. 1361-77.

[6] T.L. Christiansen and M.A.J. Somers: Scr. Mater., 2004, vol. 50, pp. 35-37.

[7] T.L. Christiansen, M.A.J. Somers, and A Sample Preparation: Metall. Mater. Trans. A, 2006, vol. 37, pp. 675-82.

[8] T.L. Christiansen, T S Hummelshøj, and M.A.J. Somers: Surf. Eng., 2010, vol. 26, pp. 242-47.

[9] F.A.P. Fernandes, T.L. Christiansen, G. Winther, and M.A.J. Somers: Acta Mater., 2015, vol. 94, pp. 271-80.

[10] S. Jegou, T.L. Christiansen, M. Klaus, C. Genzel, and M.A.J. Somers: Thin Solid Films, 2013, vol. 530, pp. 71-76.

[11] T.L. Christiansen and M.A.J Somers: Mater. Sci. Eng. A, 2006, vol. 424, pp. 181-89.

[12] B. Brink, K. Ståhl, T.L. Christiansen, and M.A.J. Somers: J. Appl. Crystallogr., 2014, vol. 47, pp. 81926.

[13] B. Brink, K. Ståhl, T.L. Christiansen, C. Frandsen, M.F. Hansen, and M.A.J. Somers: Compositiondependent variation of magnetic properties and interstitial ordering in homogeneous expanded austenite, DTU-Technical university of Denmark, Lyngby, Denamrk, unpublished research, 2015.

[14] T.L. Christiansen and M.A.J. Somers: Mater. Sci. Forum, 2004, vol. 443-444, pp. 91-94.

[15] T.L. Christiansen and M.A.J. Somers: Metall. Mater. Trans. A, 2008, vol. 40, pp. 1791-98.

[16] M.A.J Somers and E.J Mittemeijer: Metall. Trans. A, 1990, Vol. 21A, pp. 189-204.

[17] F. Bottoli, G. Winther, T.L. Christiansen, and M.A.J. Somers: Metall. Mater. Trans. A, 2015, vol. 46, pp. 2579-90.

[18] F. Bottoli, G. Winther, T.L. Christiansen, and M.A.J. Somers: Metall. Mater. Trans. A, 2015, vol. 46, 
pp. 5201-16.

[19] F. Bottoli, G. Winther, T.L. Christiansen, K. V. Dahl, and M.A.J. Somers: Metall. Mater. Trans. A, 2016, in print

[20] B.E. Warren: X-Ray Diffraction, Courier Dover Publications, New York, USA, 1969.

[21] U. Welzel, J. Ligot, P. Lamparter, A.C. Vermeulen, and E.J. Mittemeijer: J. Appl. Crystallogr., 2005, vol. 38, pp. 1-29.

[22] A. Kumar, U. Welzel, and E.J. Mittemeijer: J. Appl. Crystallogr., 2006, vol. 39, pp. 633-46.

[23] W. Voigt: Lehrbuch Der Kristallphysik, Teubner, Leipzig, 1910.

[24] A. Reuss: Z. Angew. Math, Mech., 1929, vol. 9, p. 49.

[25] H. Neerfeld: Mitt. K. Wilh.Inst. Eisenforschg., 1942, vol. 24, pp. 61-70.

[26] R. Hill: Proc.Phys. Soc. London, 1952, vol. 65, pp. 349-54.

[27] R.W. Wook and F. Witt: J. Appl. Phys., 1965, vol. 7, pp. 2169-71.

[28] E. Kröner: Z. Phys., 1958, vol. 151, pp. 504-18.

[29] J.D. Eshelby: Proc. R. Soc. A., 1957, vol. 241, pp. 376-96.

[31] J.C. Stinville, J. Cormier, C. Templier, and P. Villechaise: Acta Mater., 2015, vol. 83, pp. 10-16.

[32] T. Takahashi, J. Burghaus, D. Music, R. Dronskowski, and J.M. Schneider: Acta Mater., 2012, vol. 60, pp. 2054-60.

[33] J.C. Stinville, P. Villechaise, C. Templier, J.P. Rivière, and M. Drouet: Acta Mater., 2010, vol. 58, pp. 2814-21.

[34] C. Templier, J.C. Stinville, P. Villechaise, P.O. Renault, G. Abrasonis, J.P. Rivière, a. Martinavičius, and M. Drouet: Surf. Coatings Technol., 2010, vol. 204, pp. 2551-58.

[35] G. Winther, L. Margulies, S. Schmidt, and H.F. Poulsen: Acta Mater., 2004, vol. 52, pp. 2863-72.

[36] H.F. Poulsen, L. Margulies, S. Schmidt, and G. Winther: Acta Mater., 2003, vol. 51, pp. 3821-30. 
[37] R. Pokharel, J. Lind, A.K. Kanjarla, R.A. Lebensohn, S.F. Li, P. Kenesei, R.M. Suter, and A.D. Rollett: Annu. Rev. Condens. Matter Phys., 2014, vol. 5, pp. 317-46.

[38] J. Oddershede, J.P. Wright, A. Beaudoin, and G. Winther: Acta Mater., 2015, vol. 85, pp. 301-13.

[39] G. Winther: Acta Mater., 2008, vol. 56, pp. 1919-32.

[40] F.N. Jespersen, J.H. Hattel, and Marcel A.J. Somers: Proceedings ASM Heat Treat. 2015, Detroit, 2015 , p. in press.

[41] F.N. Jespersen, J.H. Hattel, and Marcel A.J. Somers: Model. Simul. Mater. Sci. Eng., 2015, in press. 


\section{Tables}

Table 1: X-ray elastic constants for $\mathrm{Fe}-12 \% \mathrm{Cr}-12 \% \mathrm{Ni}$ and for $\gamma^{\prime}-\mathrm{Fe}_{4} \mathrm{~N}$ for the $\{111\}$ and $\{200\}$ family planes calculated with the Reuss grain interaction models [9]. The X-ray elastic constant for $\gamma^{\prime}-\mathrm{Fe}_{4} \mathrm{~N}$ were calculated for crystallographically and elastically isotropic polycrystals [21] using $\mathrm{s}_{11}=4.36 \mathrm{MPa}^{-1}, \mathrm{~s}_{22}=1.33 \mathrm{MPa}^{-1}$ and $\mathrm{s}_{44}=21.75 \mathrm{MPa}^{-1}$ as single crystal elastic constants for $\gamma^{\prime}-\mathrm{Fe}_{4} \mathrm{~N}$ [32]. The values are given in $10^{-6} \mathrm{MPa}^{-1}$.

\begin{tabular}{cccccc}
\hline \multicolumn{3}{c}{ Reuss GIM } \\
\hline & \multicolumn{3}{c}{ Fe-12\%Cr-12\%Ni } & & \multicolumn{2}{c}{$\boldsymbol{\gamma}^{3}-\mathrm{Fe}_{4} \mathbf{N}$} \\
\cline { 2 - 3 } \cline { 5 - 6 } \cline { 5 - 6 }$S_{1}^{h k l}$ & 111 & 200 & & 111 & 200 \\
\cline { 2 - 6 } $1 / 2 S_{2}^{h k l}$ & -0.7 & -4.3 & & -3.06 & -1.33 \\
\hline
\end{tabular}




\section{Figure captions}

Figure 1: Reflected light micrographs of the annealed (a) and deformed $\varepsilon=0.5$ (b) EN 1.4369 LTN at 703K $\left(430^{\circ}\right)$ for $20 \mathrm{~h}$

Figure 2: X-ray diffractograms of EN 1.4369 after LTN $\left(703 \mathrm{~K}\left(430^{\circ} \mathrm{C}\right), 20 \mathrm{~h}\right)$ of as-received and tensilestrained conditions.

Figure 3: GD-OES nitrogen and carbon concentration profiles for EN 1.4369 after LTN $\left(703 \mathrm{~K}\left(430{ }^{\circ} \mathrm{C}\right), 20 \mathrm{~h}\right)$ of as-received and tensile-strained conditions.

Figure 4: Slopes $\Delta\left\langle d_{\psi}^{h k l}\right\rangle / \Delta \sin ^{2} \psi$ (a) and intercepts, $\left\langle d_{\psi=0}^{h k l}\right\rangle$, (b) obtained from the measurement at different depth after successive layer removal for the annealed and deformed samples.

Figure 5: Reflected light micrographs of the annealed (a) and deformed $\varepsilon=0.5$ (b) EN 1.4369 LTNC at $693 \mathrm{~K} .$.

Figure 6: X-ray diffractograms of EN 1.4369 after LTNC $\left(693 \mathrm{~K}\left(420^{\circ} \mathrm{C}\right)\right.$, 20h) of as-received and tensilestrained conditions.

Figure 7: GD-OES profiles of nitrogen and carbon for EN 1.4369 annealed or deformed and subsequently nitrocarburized at $693 \mathrm{~K}\left(420^{\circ} \mathrm{C}\right), 20 \mathrm{~h}$.

Figure 8: Hardness profile and GD-OES profile of total interstitial content in the EN 1.4369 annealed and tensile deformed $(\varepsilon=0.5)$ samples nitrocarburized at $693 \mathrm{~K}\left(420^{\circ} \mathrm{C}\right), 20 \mathrm{~h}$. 
Figure 9: Slopes, ${ }^{\Delta\left\langle d_{\psi}^{h k l}\right\rangle} /_{\Delta \sin ^{2} \psi}$, (a) and intercepts, $\left\langle d_{\psi=0}^{h k l}\right\rangle$, (b) of the $\sin ^{2} \psi$ plots for nitrocarburized EN 1.4369 in annealed and in strained condition, as obtained for 111 and 200 line profiles.

Figure 10: Dependence of strain-free lattice parameter, $a_{\varepsilon=0}$, on depth for all investigated samples calculated using the stainless steel XEC (SS-XEC) (a) and $\mathrm{Fe}_{4} \mathrm{~N}$ XEC (b). In both cases, the lattice parameter is the average of those derived from 111 and 200 reflections for interpolation in the strain-free direction of the $\sin ^{2} \psi$ relations.

Figure 11: Stress-depth distributions obtained from the slope in $d_{\psi}-\sin ^{2} \psi$ dependencies (Fig. 4a), applying Xray elastic constants for stainless steel (a) and $\gamma^{\prime}-\mathrm{Fe}_{4} \mathrm{~N}(\mathrm{~b})$, adopting the Reuss grain interaction model. 
Figure 1: Reflected light micrographs of the annealed (a) and deformed $\varepsilon=0.5$ (b) EN $1.4369 \mathrm{LTN}$ at $703 \mathrm{~K}\left(430^{\circ} \mathrm{C}\right)$ for $20 \mathrm{~h}$. 


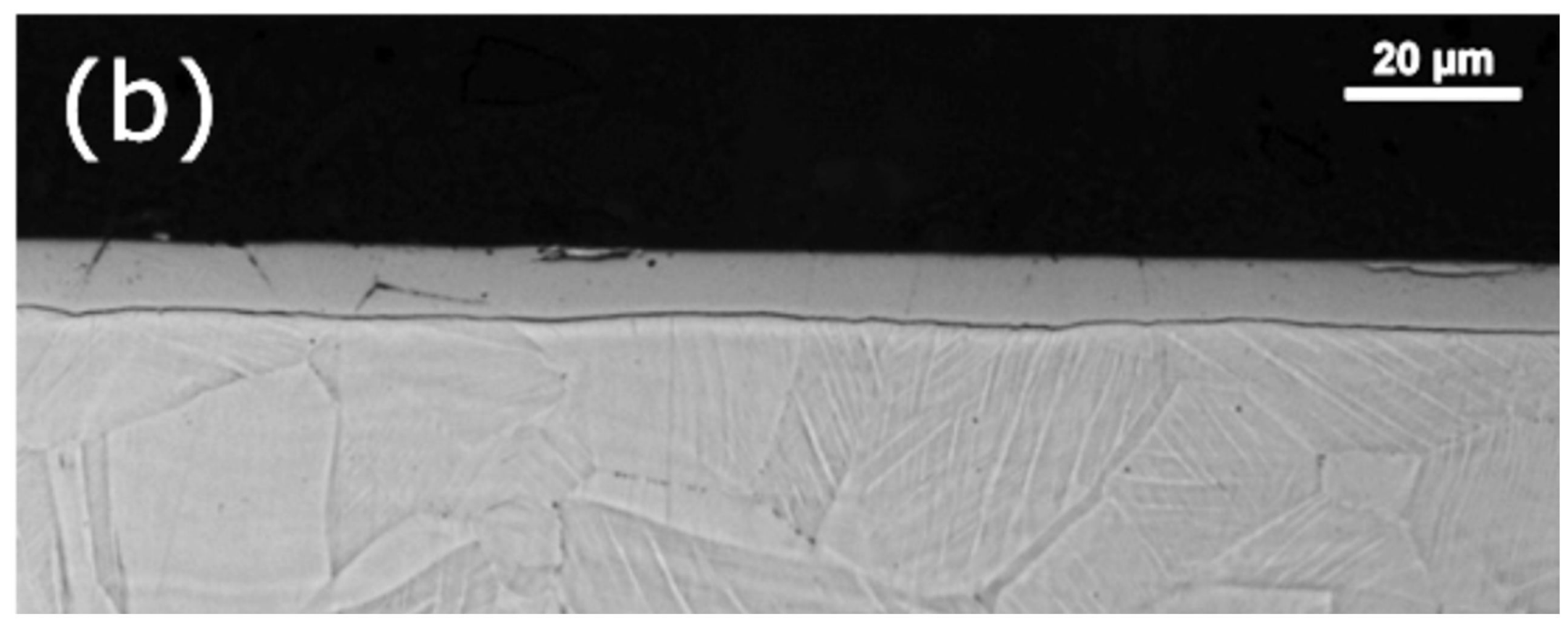

Figure 1: Reflected light micrographs of the annealed (a) and deformed $\varepsilon=0.5$ (b) EN $1.4369 \mathrm{LTN}$ at $703 \mathrm{~K}\left(430^{\circ} \mathrm{C}\right)$ for $20 \mathrm{~h}$. 


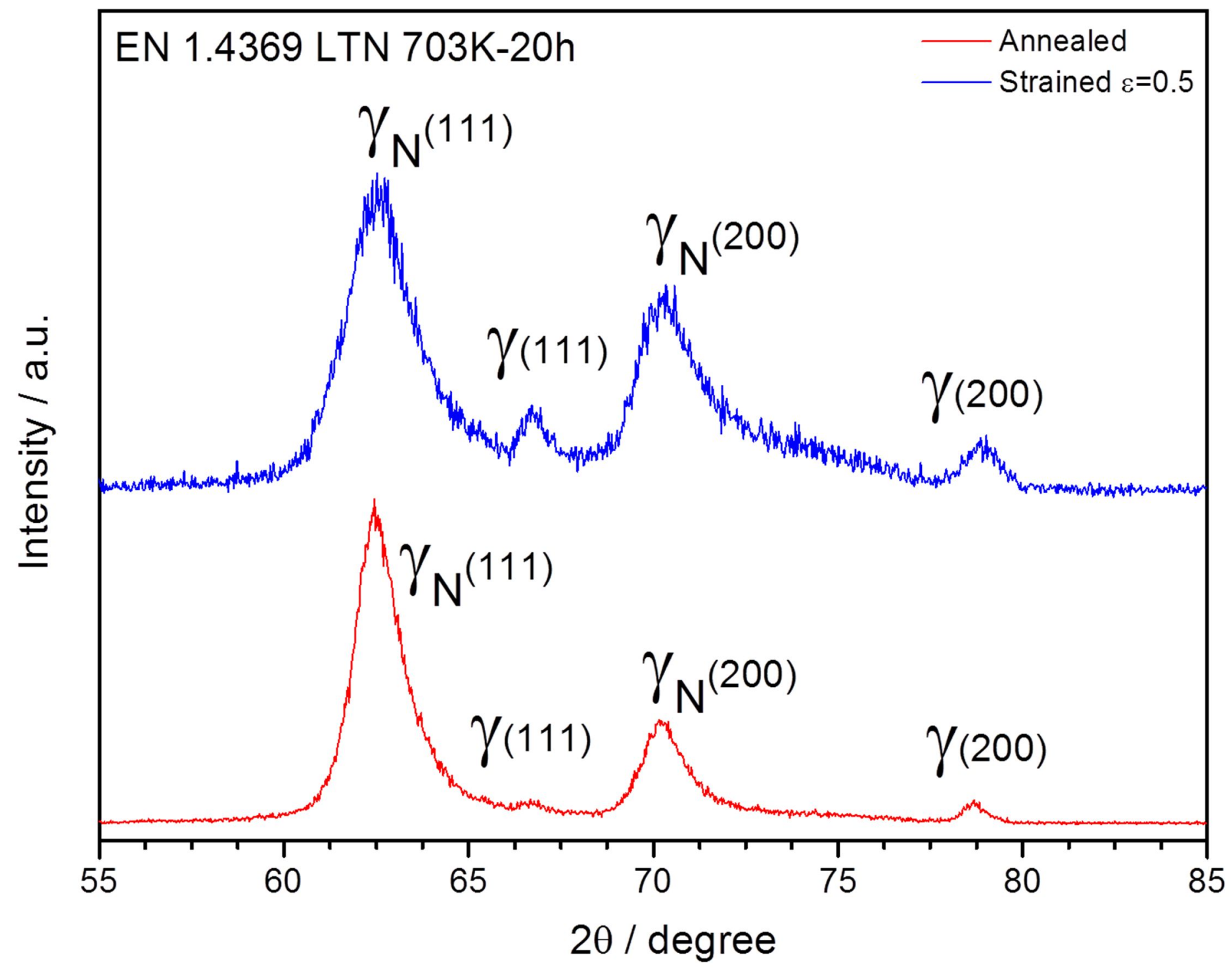

Figure 2: X-ray diffractograms of EN 1.4369 after LTN $\left(703 \mathrm{~K}\left(430^{\circ} \mathrm{C}\right), 20 \mathrm{~h}\right)$ of as-received and tensile-strained conditions. 
Figure 3

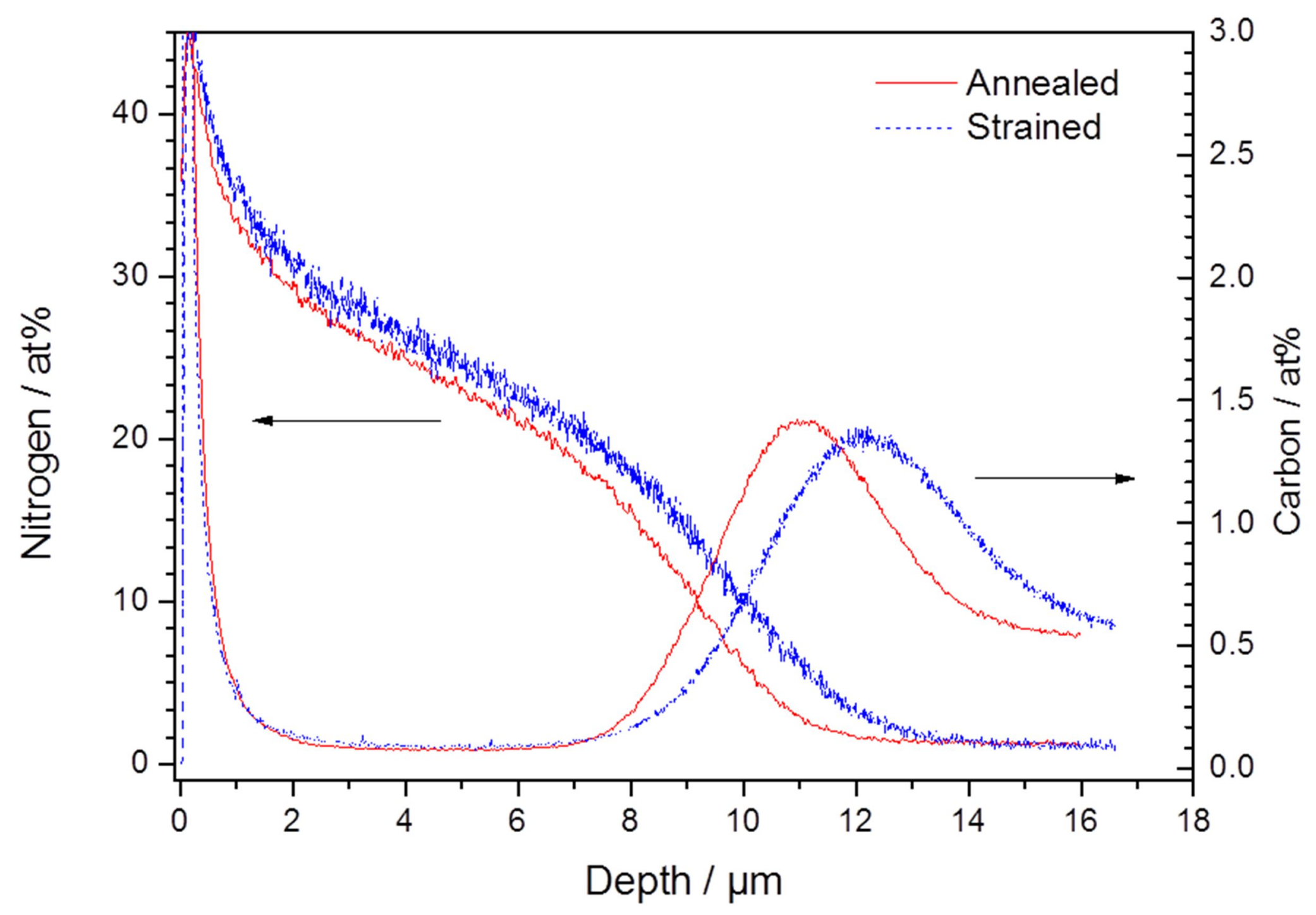

Figure 3: GD-OES nitrogen and carbon concentration profiles for EN 1.4369 after $\operatorname{LTN}\left(703 \mathrm{~K}\left(430^{\circ} \mathrm{C}\right), 20 \mathrm{~h}\right)$ of as-received and tensile-strained conditions. 
Fig. $4 a$

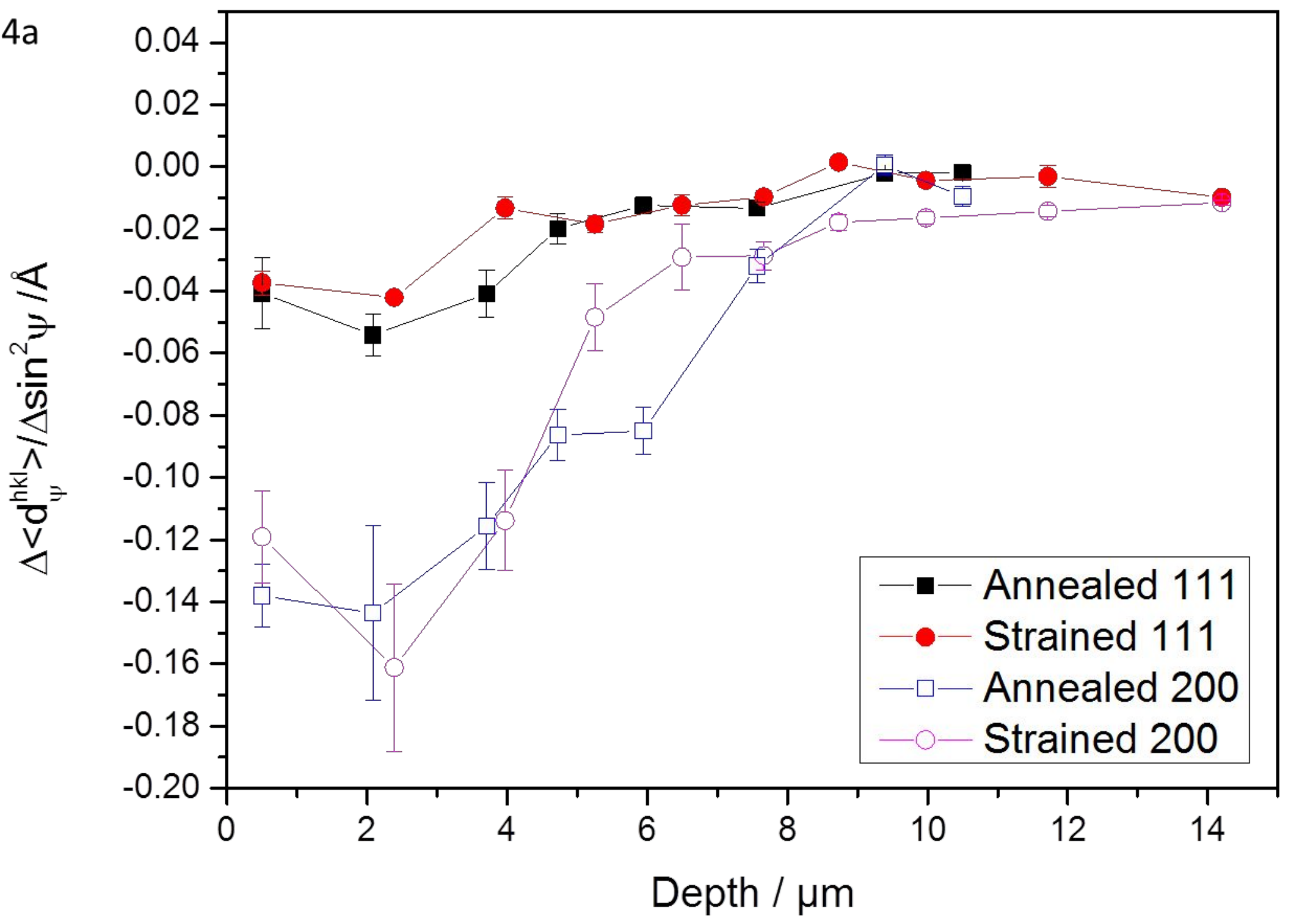

Figure 4: Slopes $\left(\Delta\left\langle\mathrm{d}_{\psi}{ }^{\mathrm{hkl}}\right\rangle\right) /\left(\Delta \sin ^{2} \psi\right)$ (a) and intercepts, $\left\langle\mathrm{d}_{\psi=0}{ }^{\mathrm{hkl}}\right\rangle$, (b) obtained from the measurement at different depth after successive layer removal for the annealed and deformed samples. 
Figure $4 b$

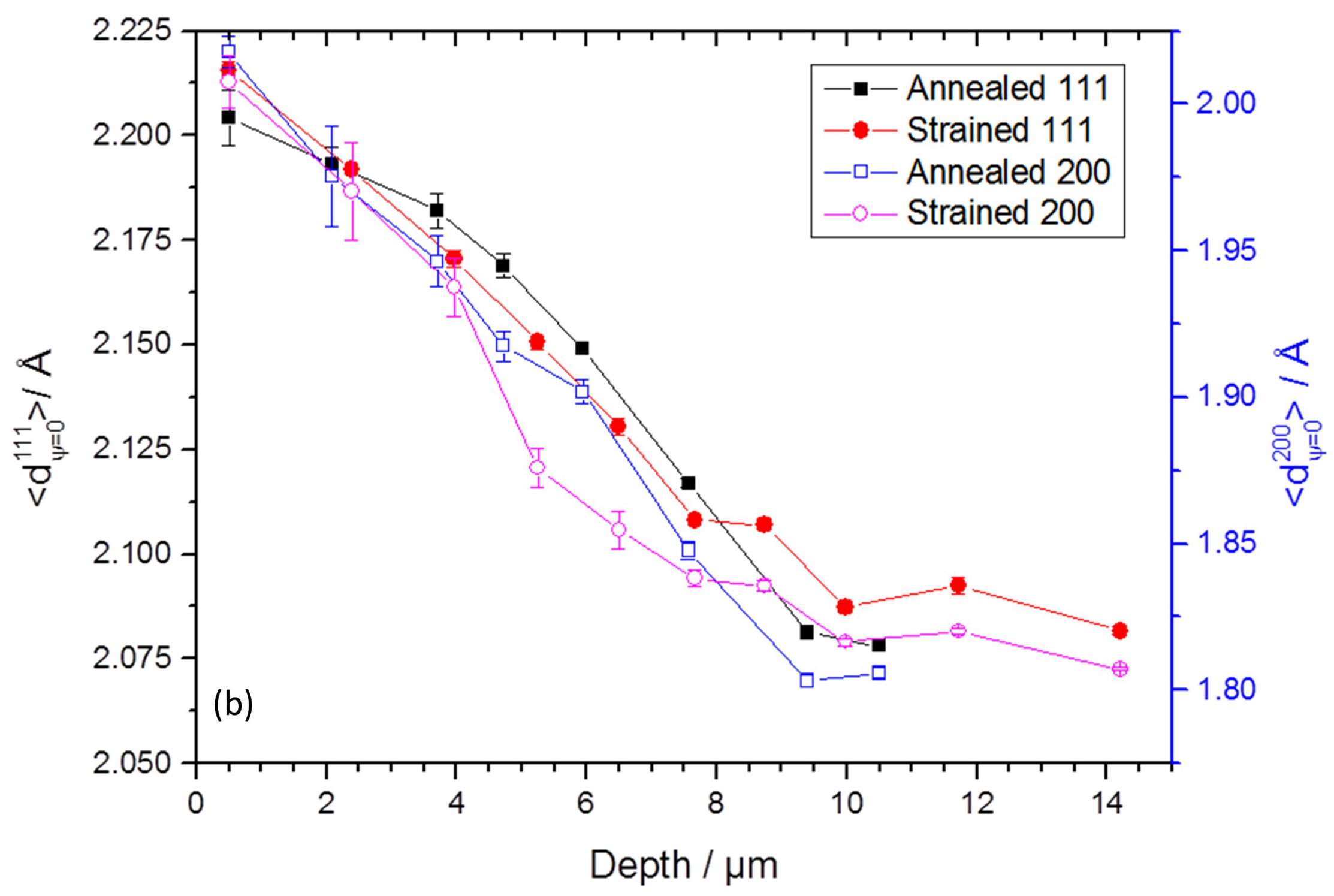

Figure 4: Slopes $\Delta\left\langle d_{\varphi=0}^{h k l}\right\rangle / \Delta \sin ^{2} \psi$ (a) and intercepts $\left\langle d_{\varphi=0}^{h k l}\right\rangle$ (b) obtained from the measurement at different depth after successive layer removal for the annealed and deformed samples 
(a)

\section{0 pm}

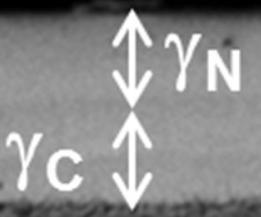

Figure 5: Reflected light micrographs of the annealed (a) and deformed $\varepsilon=0.5$ (b) EN $1.4369 \mathrm{LTNC}$ at $693 \mathrm{~K}\left(420^{\circ} \mathrm{C}\right)$ for $20 \mathrm{~h}$. 


\section{Figure $5 b$}

\section{(b)}

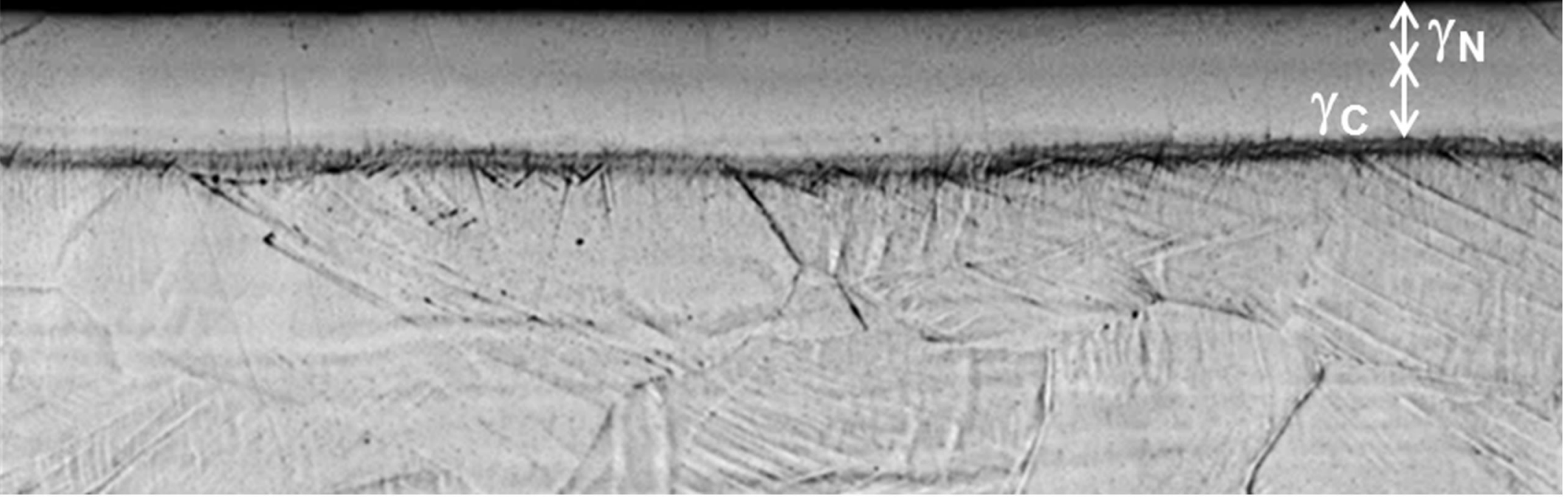

Figure 5: Reflected light micrographs of the annealed (a) and deformed $\varepsilon=0.5$ (b) EN $1.4369 \mathrm{LTNC}$ at $693 \mathrm{~K}\left(420^{\circ} \mathrm{C}\right)$ for $20 \mathrm{~h}$. 


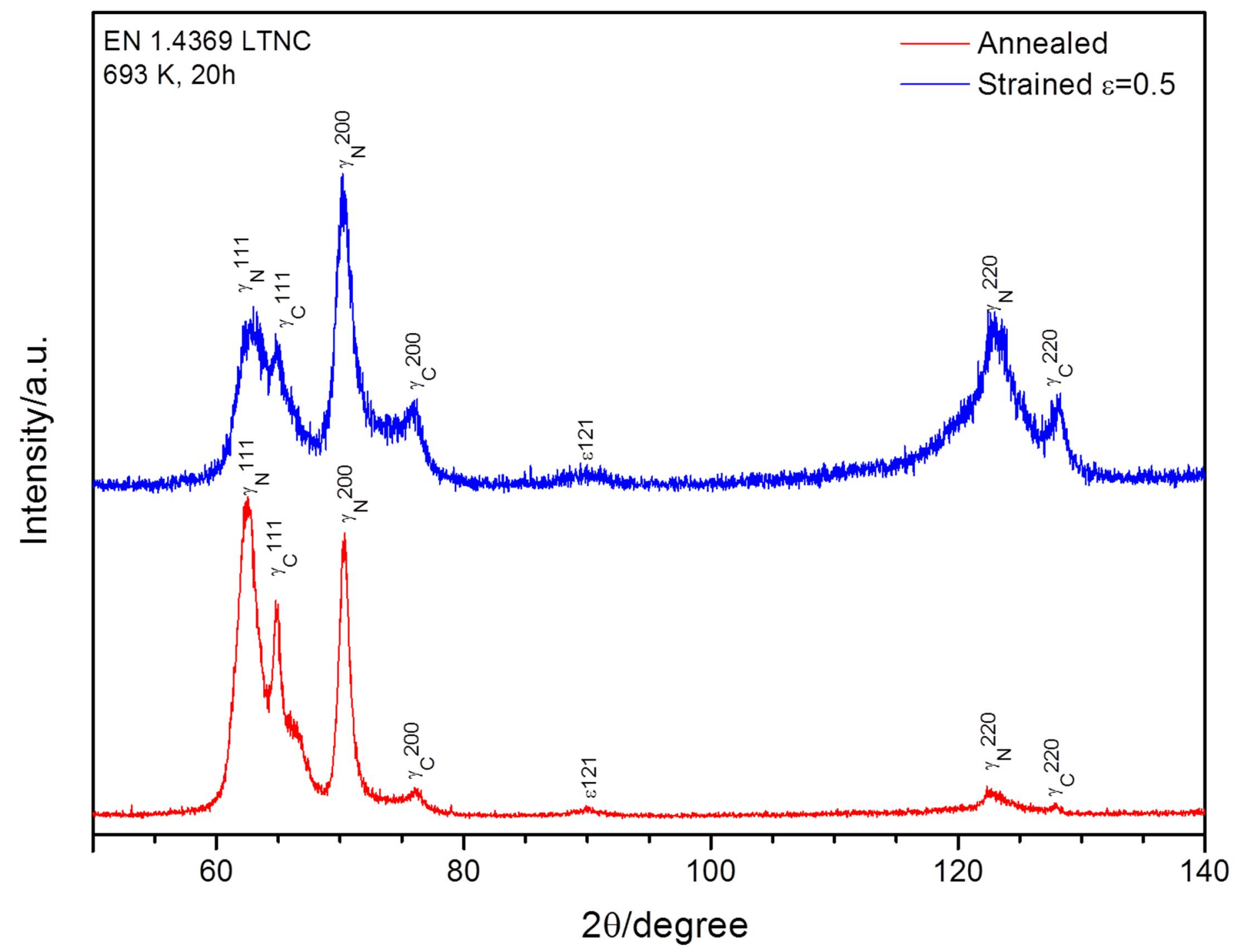

Figure 6: X-ray diffractograms of EN 1.4369 after LTNC $\left(693 \mathrm{~K}\left(420^{\circ} \mathrm{C}\right)\right.$, 20h) of as-received and tensile-strained conditions. 


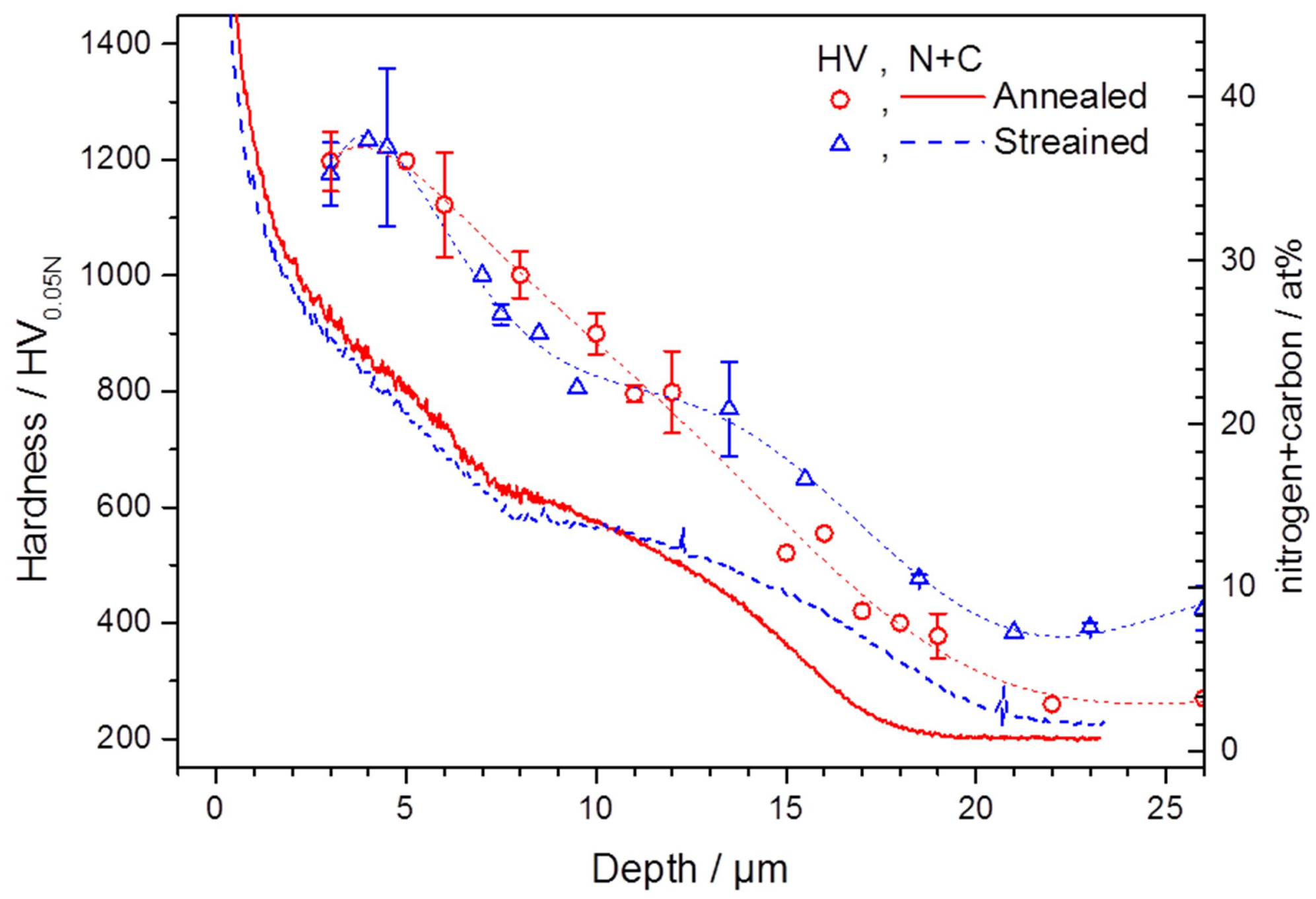

Figure 8: Hardness profile and GD-OES profile of total interstitial content in the EN 1.4369 annealed and tensile deformed $(\varepsilon=0.5)$ samples nitrocarburized at $693 \mathrm{~K}\left(420^{\circ} \mathrm{C}\right), 20 \mathrm{~h}$. 
Fig. 9a.

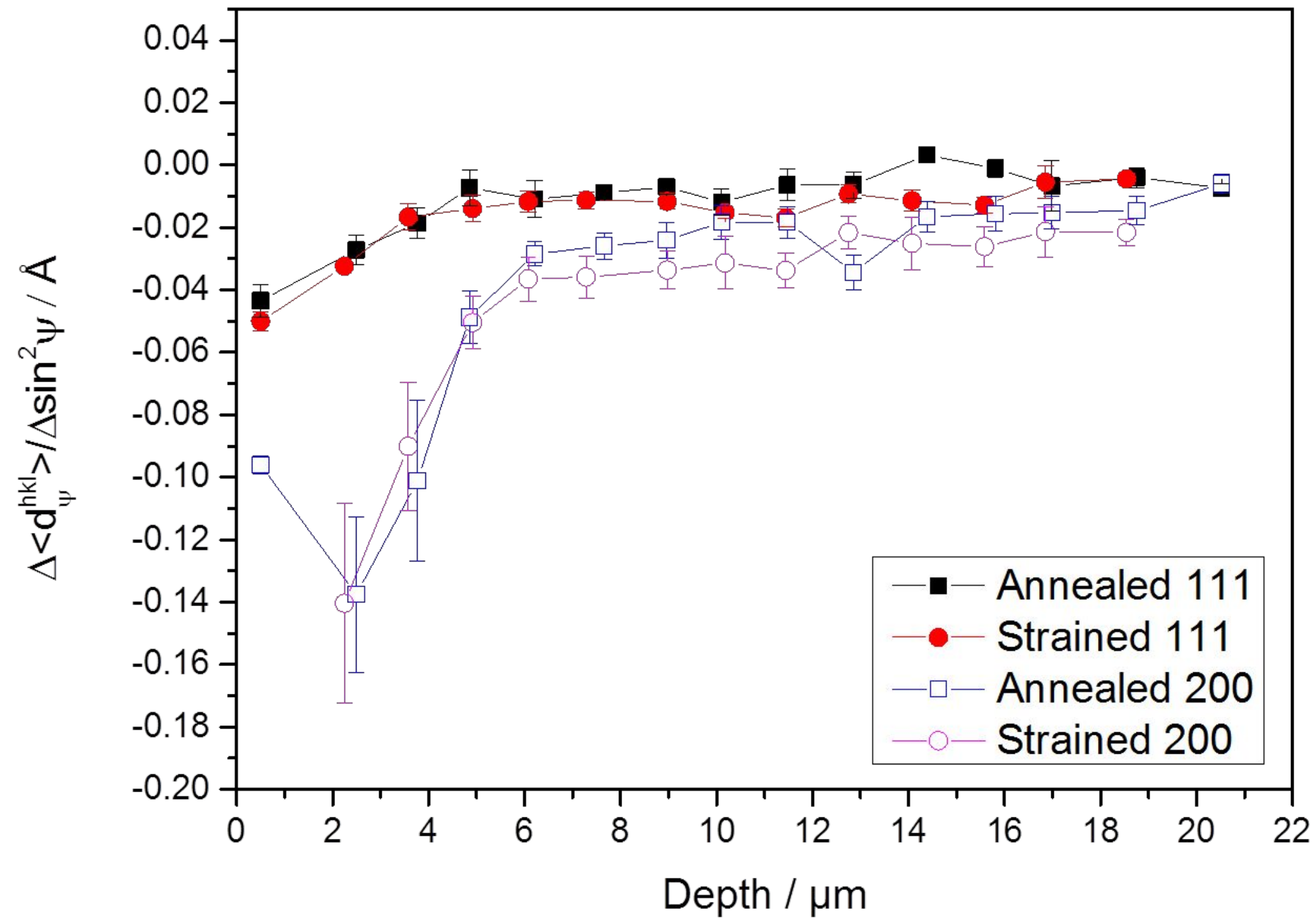

Figure 9: Slopes, ${ }^{\Delta\left\langle d_{\psi}^{h k l}\right\rangle} /{ }_{\Delta \sin ^{2} \psi}$, (a) and intercepts, $\left\langle d_{\psi=0}^{h k l}\right\rangle$, (b) of the $\sin ^{2} \psi$ plots for nitrocarburized EN 1.4369 in annealed and in strained condition, as obtained for 111 and 200 line profiles 


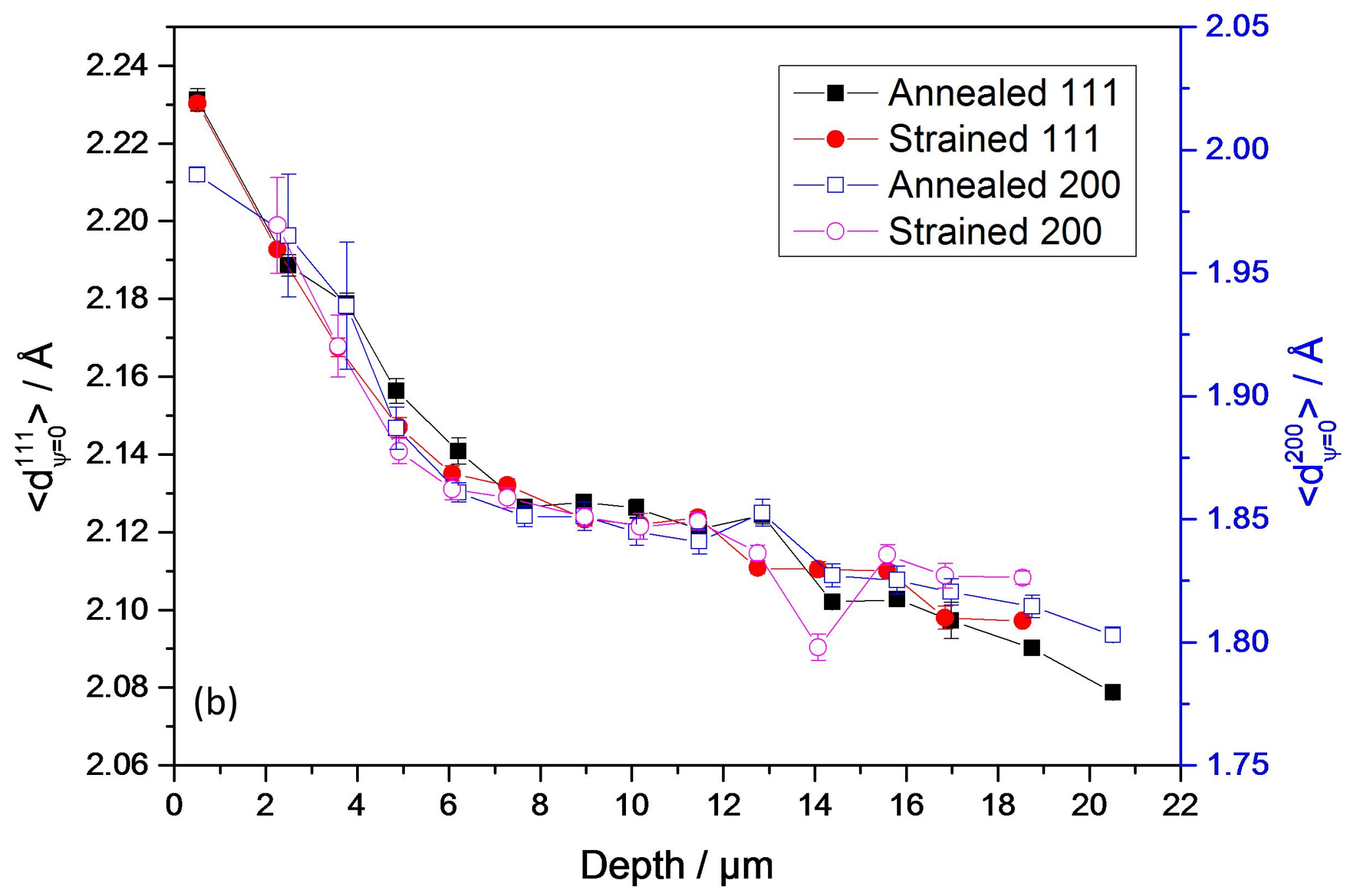

Figure 9: Slopes $\Delta\left\langle d_{\varphi=0}^{h k l}\right\rangle / \Delta \sin ^{2} \psi$ (a) and intercepts $\Delta\left\langle d_{\varphi=0}^{h k l}\right\rangle$ (b) of the $\sin ^{2} \psi$ plots for nitrocarburized EN 1.4369 in annealed in strained condition and derived from 111 and 200 line profiles. 


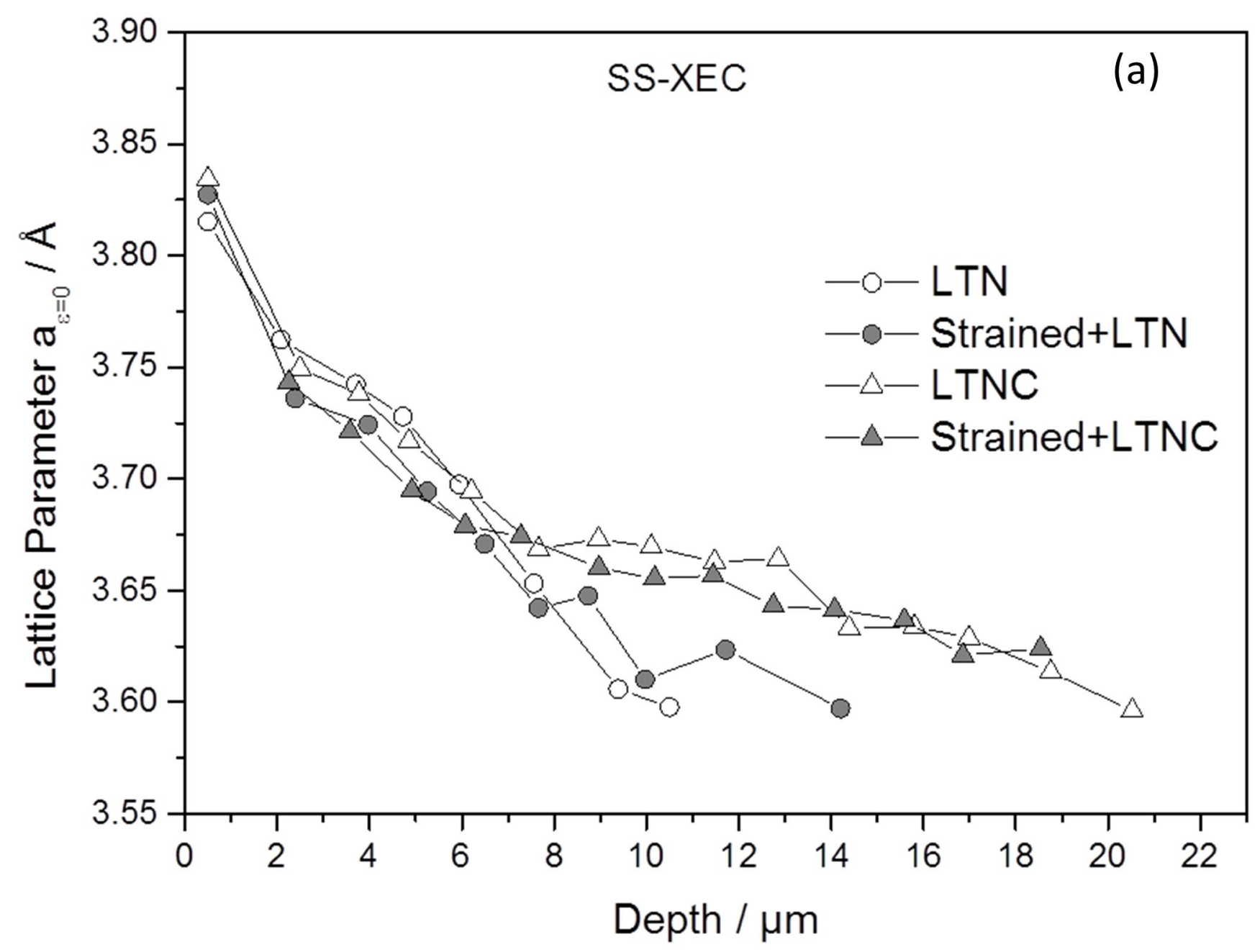

Figure 10: Dependence of strain-free lattice parameter, $a_{\varepsilon=0}$, on depth for all investigated samples calculated using the stainless steel XEC (SS-XEC) (a) and $\mathrm{Fe}_{4} \mathrm{~N} \mathrm{XEC} \mathrm{(b).} \mathrm{In} \mathrm{both}$ cases, the lattice parameter is the average of those derived from 111 and 200 reflections for interpolation in the strain-free direction of the $\sin ^{2} \psi$ relations. 


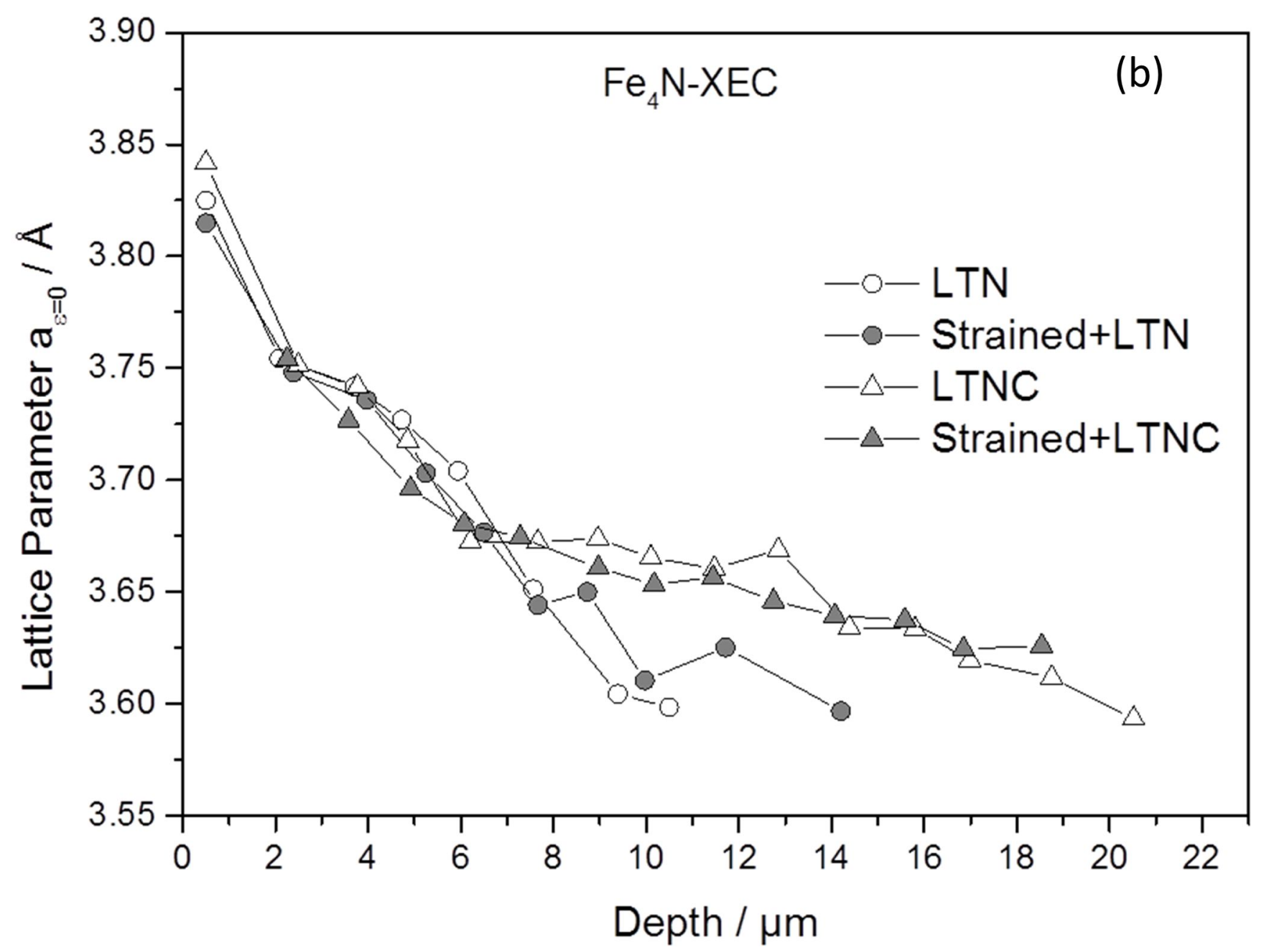

Figure 10: Dependence of strain-free lattice parameter, $a_{\varepsilon=0}$, on depth for all investigated samples calculated using the stainless steel XEC (SS-XEC) (a) and $\mathrm{Fe}_{4} \mathrm{~N} \mathrm{XEC} \mathrm{(b).} \mathrm{In} \mathrm{both}$ cases, the lattice parameter is the average of those derived from 111 and 200 reflections for interpolation in the strain-free direction of the $\sin ^{2} \psi$ relations. 


\section{Figure $11 a$}

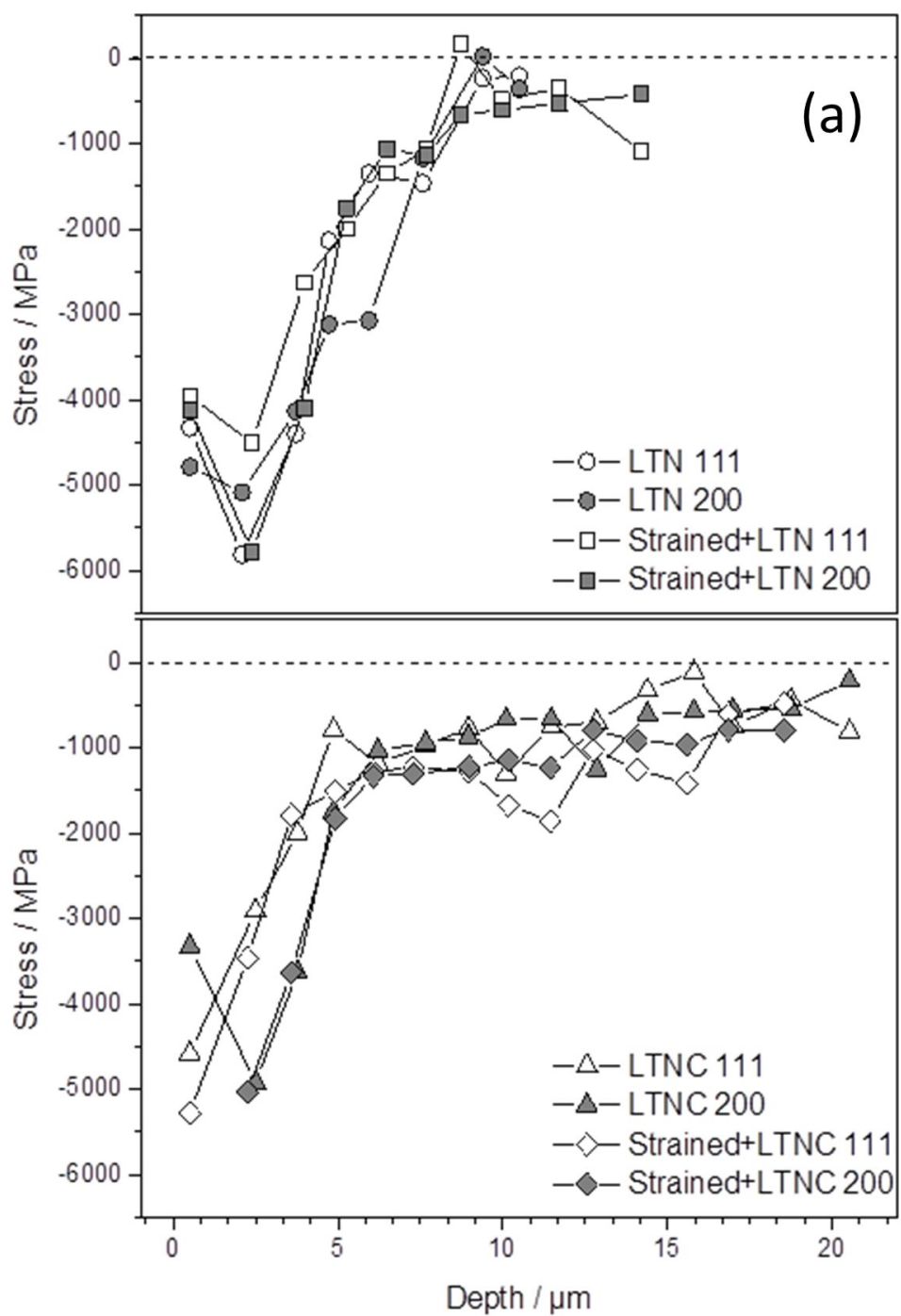

Figure 11: Stress-depth distributions obtained from the slope in $d_{\psi}-\sin ^{2} \psi$ dependencies (Fig. 4a), applying X-ray elastic constants for stainless steel (a) and $\gamma^{\prime}-\mathrm{Fe}_{4} \mathrm{~N}(\mathrm{~b})$, adopting the Reuss grain interaction model. 


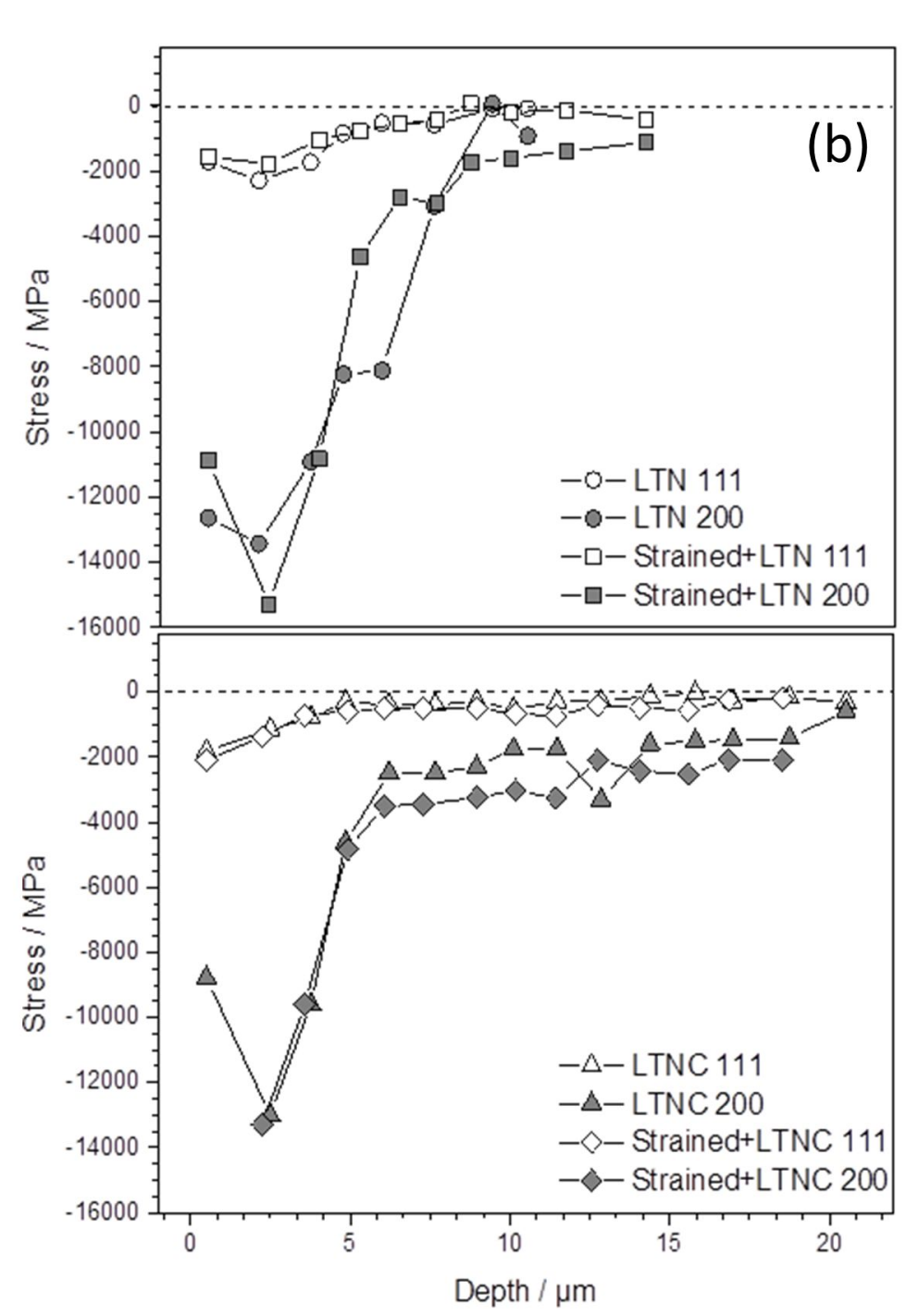

Figure 11: Stress-depth distributions obtained from the slope in $d_{\psi}-\sin ^{2} \psi$ dependencies (Fig. 4a), applying X-ray elastic constants for stainless steel (a) and $\gamma^{\prime}-\mathrm{Fe}_{4} \mathrm{~N}(\mathrm{~b})$, adopting the Reuss grain interaction model. 
Table 1: X-ray elastic constants for $\mathrm{Fe}-12 \% \mathrm{Cr}-12 \% \mathrm{Ni}$ and for $\gamma^{\prime}-\mathrm{Fe}_{4} \mathrm{~N}$ for the $\{111\}$ and $\{200\}$ family planes calculated with the Reuss grain interaction models [9]. The X-ray elastic constant for $\gamma^{\prime}-\mathrm{Fe}_{4} \mathrm{~N}$ were calculated for crystallographically and elastically isotropic polycrystals [21] using $s_{11}=4.36 \mathrm{MPa}^{-1}, \mathrm{~s}_{22}=1.33 \mathrm{MPa}^{-1}$ and $\mathrm{S}_{44}=21.75 \mathrm{MPa}^{-1}$ as single crystal elastic constants for $\gamma^{\prime}-\mathrm{Fe}_{4} \mathrm{~N}$ [31]. The values are given in $10^{-6} \mathrm{MPa}^{-1}$.

\begin{tabular}{|c|c|c|c|c|}
\hline \multicolumn{5}{|c|}{ Reuss GIM } \\
\hline & \multirow{2}{*}{\multicolumn{2}{|c|}{$\begin{array}{c}\mathrm{Fe}-12 \% \mathrm{Cr}-12 \% \mathrm{Ni} \\
\text { XEC }\end{array}$}} & \multirow{2}{*}{\multicolumn{2}{|c|}{$\begin{array}{c}\gamma^{\prime}-\mathrm{Fe}_{4} \mathrm{~N} \\
\text { XEC }\end{array}$}} \\
\hline & & & & \\
\hline & 111 & 200 & 111 & 200 \\
\hline$S_{1}^{h k l}$ & -0.7 & -4.3 & -3.06 & -1.33 \\
\hline $1 / 2 S_{2}^{h k l}$ & 4.3 & 15 & 10.9 & 5.68 \\
\hline
\end{tabular}

